\title{
GCAP neuronal calcium sensor proteins mediate photoreceptor cell death in the rd3 mouse model of LCA12 congenital blindness by involving endoplasmic reticulum stress
}

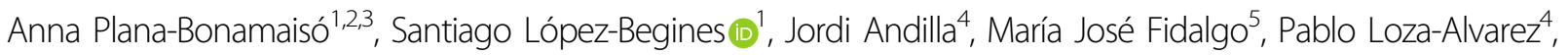 \\ Josep María Estanyol $\mathbb{1}^{5}$, Pedro de la Villa ${ }^{6,7}$ and Ana Méndez (10),2,3
}

\begin{abstract}
Loss-of-function mutations in the retinal degeneration 3 (RD3) gene cause inherited retinopathy with impaired rod and cone function and fast retinal degeneration in patients and in the natural strain of $r d 3$ mice. The underlying physiopathology mechanisms are not well understood. We previously proposed that guanylate cyclase-activating proteins (GCAPs) might be key $\mathrm{Ca}^{2+}$-sensors mediating the physiopathology of this disorder, based on the demonstrated toxicity of GCAP2 when blocked in its $\mathrm{Ca}^{2+}$-free form at photoreceptor inner segments. We here show that the retinal degeneration in $r d 3$ mice is substantially delayed by GCAPs ablation. While the number of retinal photoreceptor cells is halved in 6 weeks in $r d 3$ mice, it takes 8 months to halve in $r d 3 / r d 3 \mathrm{GCAPs}^{-1-}$ mice. Although this substantial morphological rescue does not correlate with recovery of visual function due to very diminished guanylate cyclase activity in $r d 3$ mice, it is very informative of the mechanisms underlying photoreceptor cell death. By showing that GCAP2 is mostly in its $C a^{2+}$-free-phosphorylated state in $r d 3$ mice, we infer that the $\left[\mathrm{Ca}^{2+}\right]_{\mathrm{i}}$ at rod inner segments is permanently low. GCAPs are therefore retained th the inner segment in their $\mathrm{Ca}^{2+}$-free, guanylate cyclase activator state. We show that in this conformational state GCAPs induce endoplasmic reticulum (ER) stress, mitochondrial swelling, and cell death. ER stress and mitochondrial swelling are early hallmarks of $r d 3$ retinas preceding photoreceptor cell death, that are substantially rescued by GCAPs ablation. By revealing the involvement of GCAPs-induced ER stress in the physiopathology of Leber's congenital amaurosis 12 (LCA12), this work will aid to guide novel therapies to preserve retinal integrity in LCA12 patients to expand the window for gene therapy intervention to restore vision.
\end{abstract}

\section{Introduction}

Synthesis of cyclic GMP (cGMP) is an essential process in photoreceptor cells of the retina, as cGMP is the signaltransducing molecule in the light response $\mathrm{e}^{1,2}$. Mutations

\footnotetext{
Correspondence: Ana Méndez (mendezzu@ub.edu)

${ }^{1}$ Department of Physiological Sciences, University of Barcelona School of Medicine - Health Science Campus of Bellvitge, L'Hospitalet de Llobregat, 08907 Barcelona, Spain

${ }^{2}$ Institute of Neurosciences, University of Barcelona, Castelldefels, 08035 Barcelona, Spain

Full list of author information is available at the end of the article.

Edited by $\mathrm{G}$. Melino
}

in a number of genes that impair or alter cGMP synthesis in rods and cones have been associated to different forms of blindness ${ }^{3-12}$. Loss-of-function mutations in the $R D 3$ gene (name from the natural strain of "retinal degeneration 3" mice, $r d 3$ locus mutated) cause Leber's congenital amaurosis 12 (LCA12) $^{13,14}$. LCA12 is characterized by rod and cone impaired function and severe vision loss from an early age, as well as rapid retinal degeneration.

The RD3 protein is required for the stability and ciliary trafficking of guanylate cyclases RetGC1 and RetGC2, responsible for cGMP synthesis ${ }^{15}$. In $r d 3$ mice the levels

\section{(c) The Author(s) 2020}

(c) (i) Open Access This article is licensed under a Creative Commons Attribution 4.0 International License, which permits use, sharing, adaptation, distribution and reproduction cc in any medium or format, as long as you give appropriate credit to the original author(s) and the source, provide a link to the Creative Commons license, and indicate if changes were made. The images or other third party material in this article are included in the article's Creative Commons license, unless indicated otherwise in a credit line to the material. If material is not included in the article's Creative Commons license and your intended use is not permitted by statutory regulation or exceeds the permitted use, you will need to obtain permission directly from the copyright holder. To view a copy of this license, visit http://creativecommons.org/licenses/by/4.0/. 
of RetGC1 and RetGC2 are dramatically decreased, and proteins are retained at the cell soma ${ }^{15}$. GCAPs (guanylate cyclase-activating proteins), that are proteins that confer $\mathrm{Ca}^{2+}$ sensitivity to RetGCs ${ }^{16-20}$ and depend on their binding to RetGCs for their stability and distribution to the outer segment, are also decreased in $r d 3$ mice $^{15,21,22}$. As a consequence, there is reduced cGMP synthesis that results in closure of cyclic nucleotide-gated channels (CNG-channels) and presumed chronic hyperpolarization of $r d 3$ photoreceptors, concomitant to loss of visual function. This phenotype mimics that of LCA1 caused by null mutations in GUCY2D (RetGC1) in humans ${ }^{23}$, or by retinal guanylate cyclase deficiency in mice (RetGC1/ RetGC2 double knockout mice ${ }^{21}$ ). However, while mice deficient in RetGC1/RetGC2 show a progressive retinal degeneration, in $r d 3$ mice the loss of photoreceptor cells progresses fast ${ }^{24}$.

RD3 was also reported to be a potent inhibitor of RetGC catalytic activity in vitro ${ }^{25}$, diminishing RetGC basal activity and competing with GCAP1 for RetGC binding. It was proposed that one role of RD3 would be to prevent RetGC activation while RetGCs traffic through the inner segment ${ }^{25}$.

Little is known about the molecular mechanisms that link the lack of RD3 with photoreceptor cell death in $r d 3$ mice. We previously proposed that the GCAP proteins could contribute to the physiopathology of retinal dystrophies characterized by rod/cone chronic hyperpolarization. This hypothesis was based on the fact that when a form of GCAP2 impaired to bind $\mathrm{Ca}^{2+}$ (with all functional EF-hands mutated, $\mathrm{EF}^{-} \mathrm{GCAP2}$ ) was expressed in living photoreceptors, it was retained at the cell soma by phosphorylation and 14-3-3 binding, resulting in severe toxicity and fast retinal degeneration ${ }^{26}$. In $r d 3$ mice, GCAPs are retained at the cell soma in a presumed context of chronic low $\left[\mathrm{Ca}^{2+}\right]_{\mathrm{i}}$. In addition, GUCA1B (GCAP2) has been reported as a modifier gene of the $r d 3$ mouse phenotype ${ }^{27}$. We hypothesized that $\mathrm{Ca}^{2+}$-free GCAPs could be critically involved in the physiopathology of LCA12.

We here tested that hypothesis by breeding $r d 3$ mice to $\mathrm{GCAPs}^{-1-}$ mice. We show that the retinal degeneration of $r d 3$ mice was drastically delayed by GCAPs ablation. While in $r d 3$ mice the number of photoreceptors was halved in 6 weeks, in $r d 3 / r d 3 \mathrm{GCAPs}^{-1-}$ it was halved in 8 months. By assessing the extent of GCAP2 phosphorylation in $r d 3$ mice, we infer that the GCAP proteins are mostly in their $\mathrm{Ca}^{2+}$-free cyclase activator state in $r d 3$ cell somas. By expressing RD3.V5 as a transient transgene in the rods of $r d 3$ mice, we confirm that RD3 localizes mostly to the inner segment compartment of rods, which is consistent with the proposed role of RD3 as a RetGC inhibitor. We show prominent induction of endoplasmic reticulum (ER) stress and mitochondrial swelling in $r d 3$ mice, that are substantially prevented by GCAPs ablation. We conclude that GCAPs mediate the physiopathology of LCA12 by triggering ER stress, and discuss the putative mechanisms by which they might do so, ultimately causing mitochondrial swelling, energy failure, and cell death.

\section{Results \\ Retinal degeneration due to RD3 deficiency is substantially rescued by GCAPs ablation}

To test the hypothesis that the GCAP proteins contribute to the physiopathology of blindness associated to the lack of functional RD3, we bred $r d 3$ mice to GCAP1/ GCAP2 double knockout mice $\left(\mathrm{GCAPs}^{-1-}\right.$ mice), to assess whether the retinal degeneration was delayed.

We first characterized the rate of retinal degeneration in the specific $r d 3$ strain used in this study (B6.Cg-Rd3rd3/ Boc), hereinafter referred to as $r d 3$ mice, as rates of degeneration vary in different $r d 3$ strains $^{24}$. As early as at postnatal day 20 (p20), $r d 3$ mice presented a thinner outer nuclear layer $(\mathrm{ONL})$ than wild-type mice (10 rows versus 12 rows of nuclei, Fig. 1a). An statistical analysis of ONL thickness performed on morphometric measurements from $\mathrm{wt} / r d 3$ and $r d 3 / r d 3$ littermate mouse retinas at $\mathrm{p} 20$, $\mathrm{p} 26$, and $\mathrm{p} 44$ revealed that in $r d 3$ mice the number of photoreceptor cells was halved in $\sim 6$ weeks (Fig. 1a, b). This is consistent with the reported rate of degeneration of $r d 3$ pigmented mouse strains ${ }^{24}$.

We confirmed that RetGC1 expression was severely reduced in $r d 3$ mice $^{15}$. RetGC1 levels were reduced to $\sim 12 \%$ of the expression in control mice at p20, Fig. 1c. The expression levels of GCAP1 and GCAP2 were reduced to 37 and $42 \%$ of the levels in control mice, Fig. 1c. A novel observation was that RetGC1 was detected by immunofluorescence analysis on retinal sections of $r d 3$ mice at the inner segment layer and perinuclear region of photoreceptors, showing a characteristic punctated staining, Fig. 1d. GCAP1 and GCAP2 were largely retained to proximal photoreceptor compartments in $r d 3$ mice, as previously described ${ }^{15}$, Fig. 1d. Specificity of the antibodies to RetGC1 and RD3 used in Fig. 1c, d is shown in Supplementary Fig. 1.

To assess whether ablation of GCAPs affected the time course of retinal degeneration in the $r d 3$ mice, we bred $r d 3$ mice to $\mathrm{GCAPs}^{-1-}$ mice. To minimize strain variation effects, the breeding was established between $r d 3 / r d 3$ $\mathrm{GCAPs}^{+/-}$mice, and homozygous $r d 3 / r d 3$ mice that were either $\mathrm{GCAPs}^{+/-}$or $\mathrm{GCAPs}^{-1-}$ littermates were compared, Fig. 2. The ONL width of $r d 3 / r d 3$ mice at $\mathrm{p} 44$ from Fig. 1 is plotted as a reference. Compared to $r d 3 / r d 3$ mice at $\mathrm{p} 44$ (ONL thickness of $20 \mu \mathrm{m}, 5$ nuclei), $r d 3 / r d 3$ $\mathrm{GCAPs}^{+/-}$showed a very minor improvement at this age $(22-24 \mu \mathrm{m}, 5-6$ nuclei, $n=4)$; while $r d 3 / r d 3 \mathrm{GCAPs}^{-1-}$ mice showed a striking improvement $(30-32 \mu \mathrm{m}, 7-8$ 

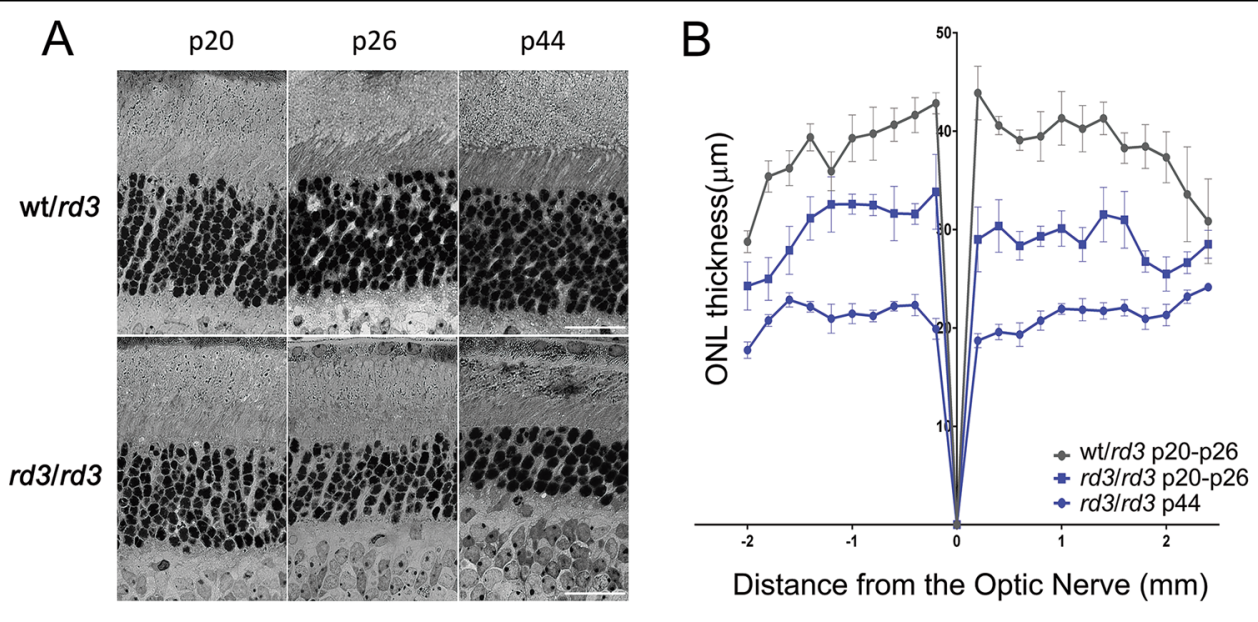

C

D
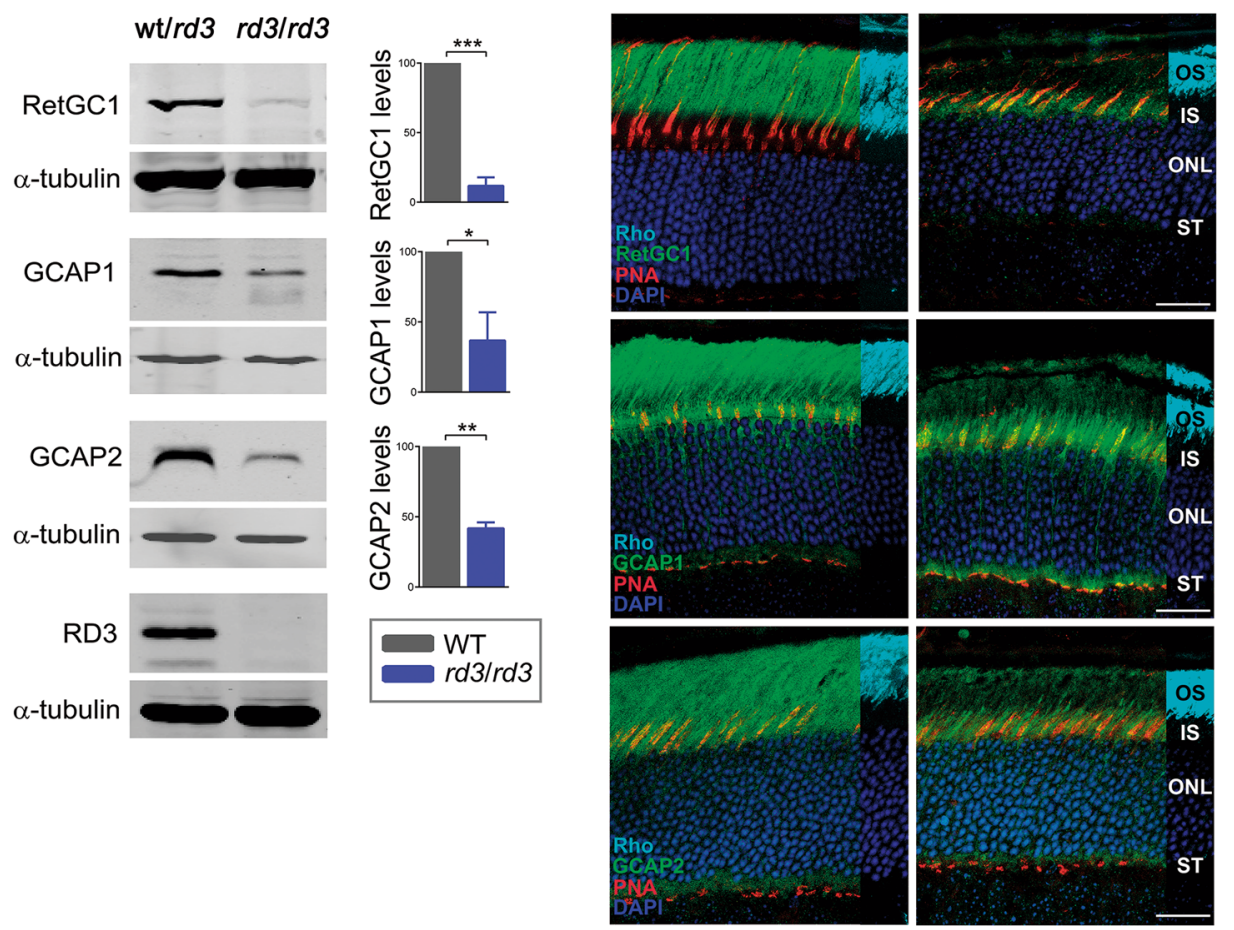

Fig. 1 Time course and molecular alterations that characterize the retinal degeneration in $r d 3$ mice strain B6.Cg-Rd3rd3/Boc. a Retinal micrographs of wild type and $r d 3 / r d 3$ mice at p20, p26, and p44 show the progressive retinal degeneration in $r d 3 / r d 3$ mice, that halves the number of photoreceptor cells at p44. Scale bar $20 \mu \mathrm{m}$. b Retinal morphometric analysis of $w t / r d 3$ and $r d 3 / r d 3$ mice at the indicated ages, showing outer nuclear layer $(\mathrm{ONL})$ length $(\mu \mathrm{m})$ at $200 \mu \mathrm{m}$ intervals from the optic nerve in the vertical meridian of the eye, superior retina to the right. Each trace represents the average measurements of four mice analyzed, with error bars indicating the standard error of the mean (SEM). $(n=2$ biological replicas at p20, and $n=2$ biological replicas at p26 for wt/rd3 and $r d 3 / r d 3 ; n=4$ biological replicas at p44 for $r d 3 / r d 3)$. c Expression levels of RetGC1, GCAP1, and GCAP2 in $r d 3 / r d 3$ mice compared to $w t / r d 3$ mice at p30. Histograms indicate the percentage of expression of each protein in rd3/rd3 mice versus wt/ rd3 mice, after normalization with a-tubulin. No RD3 protein is detected in $r d 3 / r d 3$ mice with an antibody generated against the RD3 C-terminus. For the determination of protein levels, three independent experiments were performed: RetGC1 (wt/rd3 versus rd3; $P<0.0001^{* * *}$ ); GCAP1 (wt/rd3 versus $r d 3 ; P<0.032^{*}$ ); and GCAP2 (wt/rd3 versus $r d 3 ; P=0.0017^{* *}$ ). $\mathbf{d}$ Immunofluorescence localization of RetGC1, GCAP1, and GCAP2 in wt/rd3 and $r d 3 / r d 3$ mice at p24. RetGC1, GCAP1, and GCAP2 signals are greatly reduced in $r d 3 / r d 3$ mice, and mostly restricted to the photoreceptor inner layer. Cones are labeled with peanut agglutinin (PNA) in red; the rod outer segment layer with anti-Rhodopsin mAb 1D4 (1 cm overlay in cyan), and nuclei are labeled with DAPI (blue). Scale bar $20 \mu \mathrm{m}$. OS, outer segment; IS, inner segment; ONL, outer nuclear layer; ST, synaptic terminals. 

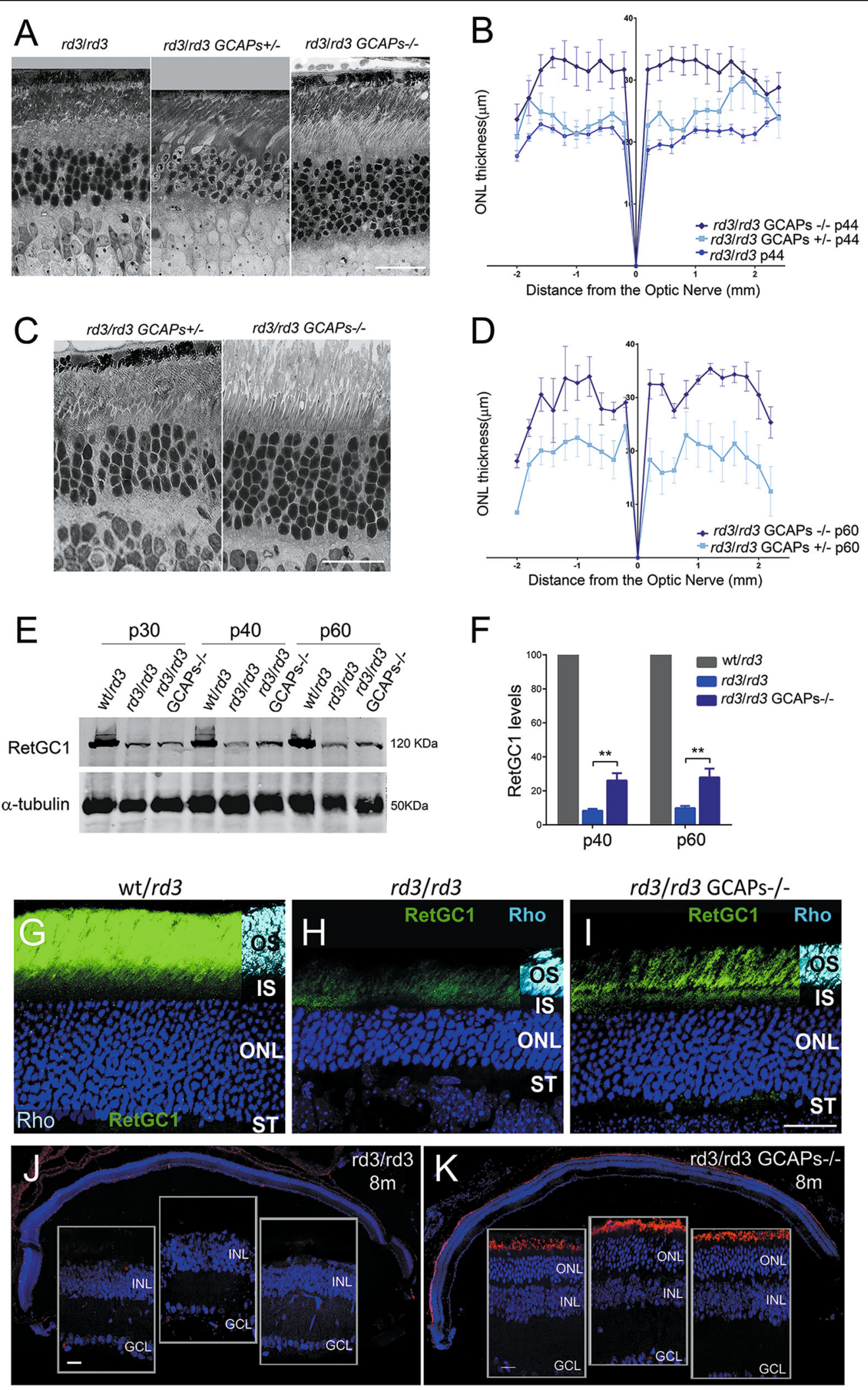

Fig. 2 (See legend on next page.) 
(see figure on previous page)

Fig. 2 Retinal degeneration in $r d 3$ mice is substantially prevented by GCAPs ablation. a Retinal morphology of $r d 3 / r d 3 ; r d 3 / r d 3$ GCAPs ${ }^{+/-}$and rd3/rd3 GCAPs ${ }^{-1-}$ mice at p44. Photoreceptor cell loss is substantially prevented in the GCAPs ${ }^{-1-}$ background. Scale bar $20 \mu \mathrm{m}$. b Retinal morphometry analysis of the indicated genotypes at p44 showing ONL length $(\mu \mathrm{m})$ along the vertical meridian of the eye. Each trace shows the average from measurements taken from four mice, with error bars showing the standard error of the mean (SEM). GCAPs removal results in preservation of $25 \%$ more photoreceptors at p44. c Morphology of the retina in rd3/rd3 GCAPs ${ }^{+/-}$and $r d 3 / \mathrm{rd}_{3} \mathrm{GCAPs}^{-1-}$ at p60. The protective effect of GCAPs ablation persists at this age. Scale bar $20 \mu \mathrm{m}$. d Statistical analysis of ONL length in $r d 3 / r d 3 \mathrm{GCAPs}^{+/-}$and $r d 3 / \mathrm{rd} \mathrm{GCAPs}^{-1-}$ retinas at p60. Results are mean \pm SEM of four biological replicas. e Level of expression of RetGC1 in $r d 3 / r_{d} 3 \mathrm{GCAPs}^{+/-}$and $r d 3 / \mathrm{rd}^{3} \mathrm{GCAPs}^{-/-}$retinas at p30, p40, and p60. RetGC1 expression levels correlate with the fraction of photoreceptors preserved. $\mathbf{f}$ Statistical analysis of RetGC1 expression levels, mean \pm SEM of three biological replicas per genotype. RetGC1 levels are not altered by the presence or absence of GCAPs at p30, consistent with rd3/rd3 and $r d 3 / r d 3 \mathrm{GCAPs}^{-1-}$ mice having a similar ONL thickness at this age. RetGC1 levels are significantly increased in the GCAPs ${ }^{-1-}$ background at p40 and p60, reflecting the extent to which photoreceptor cells are preserved at these ages. Unpaired $t$-test $\left(r d 3 / r d 3\right.$ versus $r d 3 / r^{\prime} d 3 \mathrm{GCAPs}^{-1-}$ at p40, $P=$ $\left.0,0023^{* *}\right)$; $\left(r d 3 / r d 3\right.$ versus $r d 3 / r d 3 \mathrm{GCAPs}^{-\prime-}$ at $\left.\mathrm{p} 60, P=0,0043^{* *}\right)$. $\mathbf{g}-\mathbf{i}$ In the absence of GCAPs, more RetGC1 distributes to the rod outer segment (ROS) layer in rd3 mice $\mathbf{i}$, than in the presence of GCAPs $\mathbf{h}$. Scale bar $20 \mu \mathrm{m}$. OS, outer segment; IS, inner segment; ONL, outer nuclear layer; ST, synaptic terminals. $\mathbf{j}, \mathbf{k}$ The protective effect of GCAPs ablation persists at 8 months. A representative retinal section of $r d 3 / r d 3$ mice at 8 months, with nuclei stained with DAPI (blue), shows a complete loss of the photoreceptor cell layer $\mathbf{j}$. A retinal section of $r d 3 / \mathrm{rd}^{3} \mathrm{GCAPs}^{-1-}$ mice at 8 months shows an outer nuclear layer with five rows of nuclei that preserve their outer segments (note the ROS layer stained with anti-rhodopsin antibody). Retinal sections are representative of three mice per genotype. Scale bar $20 \mu \mathrm{m}$.

nuclei, $n=4)$, Fig. 2a, b. This substantial rescue effect of GCAPs ablation was preserved at p60 (Fig. 2c, d), when four biological replicas per genotype were analyzed. In the absence of GCAPs, the $r d 3$ mice preserved $75 \%$ of their photoreceptors at p60; while in the presence of GCAPs they preserved $<50 \%$.

This substantial preservation of photoreceptors in the absence of GCAPs correlated with an increase in RetGC1 levels in $r d 3 / r d 3 \mathrm{GCAPs}^{-1-}$ retinas (Fig. 2e, f). Quite surprisingly, RetGC1 in $r d 3 / r d 3 \mathrm{GCAPs}^{-1-}$ mice was distributed to rod outer segments (ROSs) to a higher extent than in $r d 3 / r d 3$ mice (Fig. $2 \mathrm{~g}, \mathrm{i}$ ).

At 8 months of age, $r d 3 / r d 3$ mice did not retain any photoreceptor cells, while $r d 3 / r d 3 \mathrm{GCAPs}^{-1-}$ mice preserved five rows of photoreceptors with visible outer segments, Fig. 2j, k.

We conclude that GCAPs ablation markedly slows down photoreceptor cell death in the $r d 3$ mice, implying that GCAP proteins are involved in the physiopathology of LCA12.

\section{Morphological rescue of rd3 retinas by GCAPs ablation does not correlate with an amelioration of visual function}

To test whether the substantial morphological rescue of $r d 3$ mice that resulted from GCAPs ablation correlated with an amelioration of visual function, light-elicited electroretinogram (ERG) responses were recorded from wt, $r d 3$ / $r d 3, \mathrm{GCAPs}^{-1-}$, and $r d 3 / r d 3 \mathrm{GCAPs}^{-1-}$ mice at $\mathrm{p} 40$.

$R d 3$ mice showed substantially reduced scotopic and photopic responses (Fig. 3), as expected based on the drastically reduced RetGC levels in these mice, as previously reported ${ }^{28}$. Despite this substantially reduced sensitivity to light, $r d 3$ mice elicited diminished but reliable responses to flashes in the scotopic and photopic range (Fig. 3), indicating that at p40 they retained some rod and cone visual function.
$\mathrm{GCAPs}^{-1-}$ mice presented reduced visual responses in the scotopic and photopic range due to the lack of GCAPs stimulation of guanylate cyclase activity, but they largely retained visual function (Fig. 3).

Strikingly, $r d 3 / r d 3$ GCAPs $^{-1-}$ mice at $\mathrm{p} 40$ yielded barely noticeable responses to flashes at either the scotopic or photopic range, despite maintaining 25\% more photoreceptor cells than $r d 3 / r d 3$ mice and higher levels of RetGC at their retinas. A possible explanation for these results is that $r d 3 / r d 3 \mathrm{GCAPs}^{-1-}$ responses reflect the lack of stimulation of RetGC activity by the GCAP proteins; whereas $r d 3 / r d 3$ mice retain GCAP stimulation of the remaining RetGC proteins.

Taken together our results show that GCAPs ablation in the $r d 3$ mice substantially prevented retinal degeneration but at the cost of impairing rather than ameliorating visual function.

\section{Subcellular localization of RD3 in retinal sections}

RD3 was described as a potent inhibitor of RetGC activity in vitro, and was predicted to localize to the inner segment layer where it could silence the cyclase during its transport to the cilium ${ }^{25}$. However, RD3 was immunolocalized to the outer segment layer of the retina in wt mice by specific antibodies against the $\mathrm{COOH}$-terminus of the protein ${ }^{15}$.

To determine RD3 subcellular localization by avoiding the use of anti-RD3 antibodies, we generated transient transgenic mice that expressed RD3 fused to a short tag (RD3.V5) in rod photoreceptors. To express RD3.V5 in rods, we made use of in vivo DNA electroporation after subretinal injection in newborn $r d 3 / r d 3$ mice with the construct pRho-RD3.V5-dsRed. RD3 was then immunolocalized at p20 using well-established anti-V5 antibodies (Methods section).

RD3.V5 showed the mosaic pattern of expression that characterizes in vivo DNA electroporation transgenesis, in 


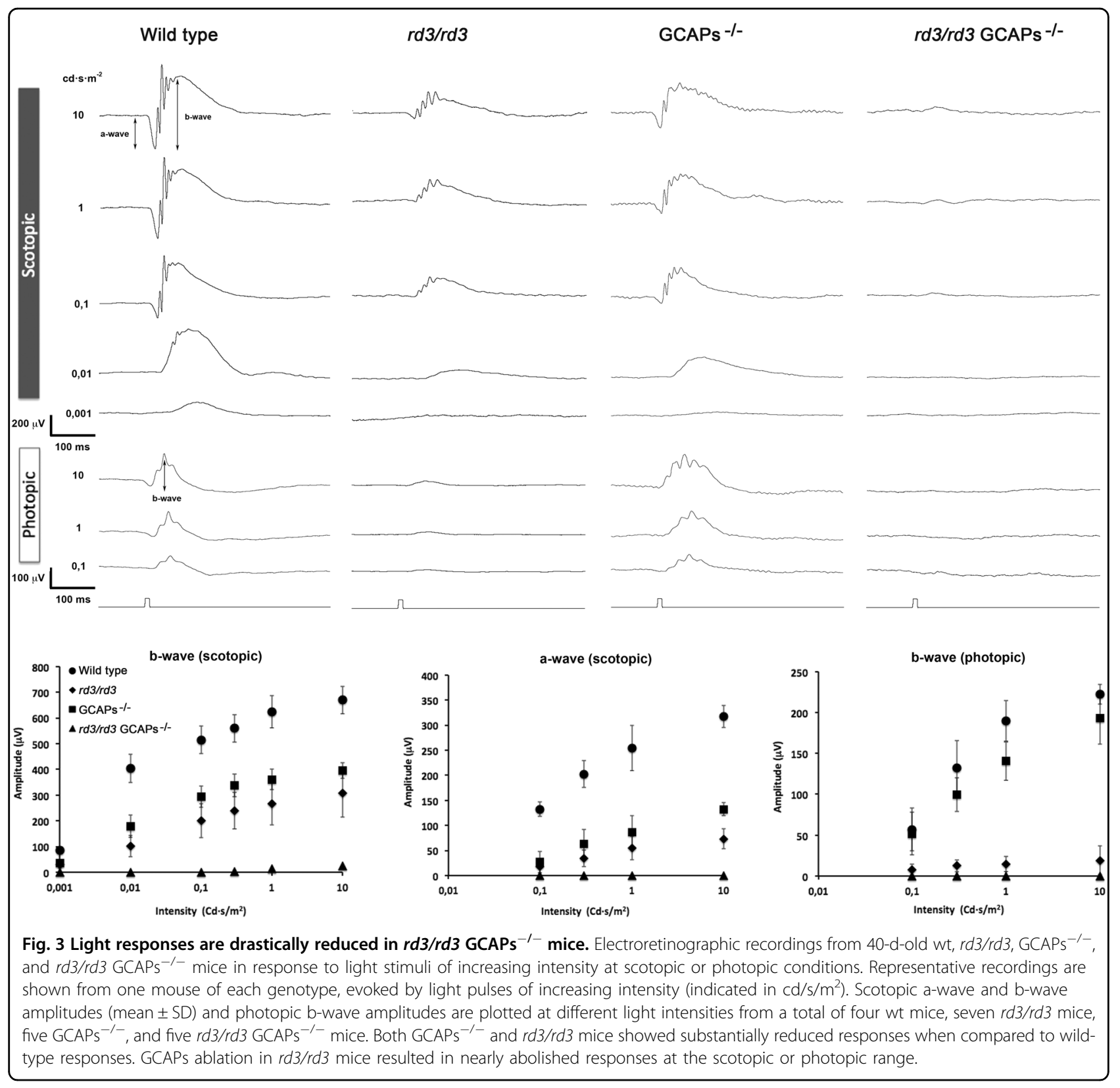

which only transfected cells express the transgene. The expression of RD3.V5 in $r d 3 / r d 3$-transfected rods restored RetGC1 expression and its localization to the outer segment, which indicated that the RD3.V5 protein was active (Fig. 4). RD3.V5 localized to the inner and outer segments of transfected cells, giving a much stronger signal at the inner segments. Particularly, there appears to be a membrane domain, probably at the connecting cilium, where the RetGC1 and RD3.V5 signals strongly colocalize (see the white signal from the merged green and magenta channels with "staple" shape, Fig. 4).

Therefore our results are in line with the results obtained by Dizhoor et al. ${ }^{29}$ that localize RD3 mainly at the inner segment, although we observe some signal at the outer segment as well. The mosaic expression excludes that this signal is unspecific, as electroporated cells are surrounded by negative control cells. Anti-V5 antibodies unspecifically stain synaptic ribbons. This signal is clearly unspecific because it is detected in transfected and untransfected cells (Fig. 4).

GCAP2 in rd3 mice is mostly in its phosphorylated $\mathrm{Ca}^{2+}$-free form, a target for 14-3-3 binding

We have previously reported that an accumulation of $\mathrm{Ca}^{2+}$-free GCAP2 at the inner segment is highly deleterious for rod cells ${ }^{26}$. In $r d 3$ photoreceptor cells, GCAP2 


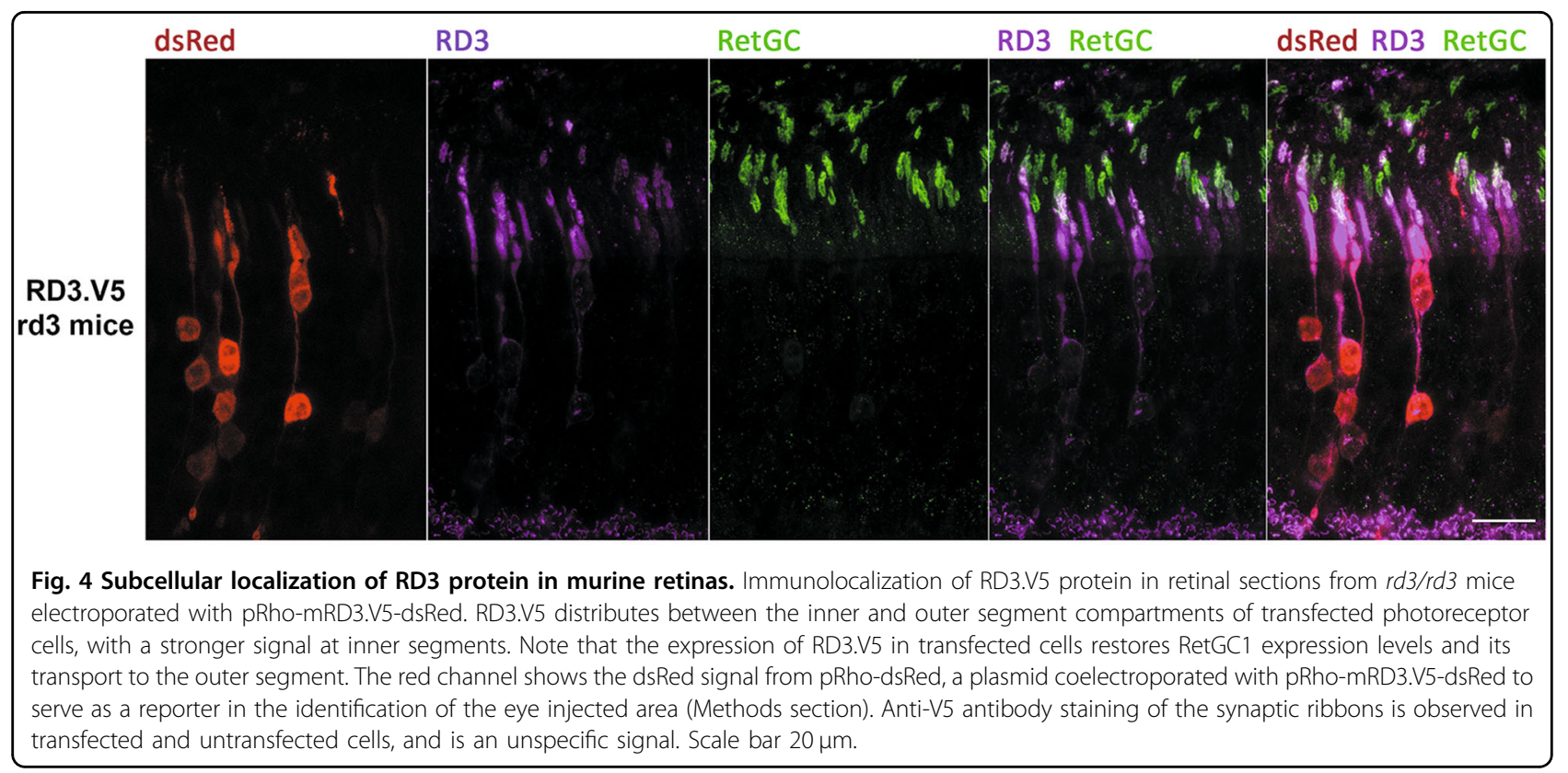

is retained at the inner segment (Fig. 1d). To test whether GCAP2 is in its $\mathrm{Ca}^{2+}$-free "deleterious" conformation in $r d 3$ mice, we analyzed GCAP2 levels of phosphorylation.

In vitro and in vivo studies have shown that GCAP2 is phosphorylated at Ser201 preferentially in its $\mathrm{Ca}^{2+}$-free form $^{26,30}$. In wt mice, $~ 50 \%$ of GCAP2 is phosphorylated when mice are reared under standard cyclic light, independently of their sacrifice in the dark or light period ${ }^{26}$. However, a GCAP2 mutant locked in its $\mathrm{Ca}^{2+}$-free form (EF ${ }^{-}$GCAP2) transgenically expressed in rods showed a much higher extent of GCAP2 phosphorylation. This indicates that the extent of GCAP2 phosphorylation in vivo reflects the fraction of GCAP2 molecules in the $\mathrm{Ca}^{2+}$-free conformation ${ }^{26}$.

The extent of GCAP2 phosphorylation in $r d 3 / r d 3$ versus wt mice was analyzed by resolving retinal homogenates at p21 in isoelectrofocusing gel strips that covered a linear $\mathrm{pH}$ gradient of 3-10 (Fig. 5a). Threefold more $r d 3 / r d 3$ protein sample $(100 \mu \mathrm{g})$ than wt sample $(25 \mu \mathrm{g})$ was loaded, in order to equilibrate the GCAP2 signal. Unphosphorylated GCAP2 presented an isoelectric point (IP) of 4.92, whereas phosphorylated GCAP2 an IP of 4.85. In wt mice, GCAP2 and GCAP2-P were present at a 1:1 ratio as originally reported. In contrast, GCAP2 and GCAP2-P were observed at a 1:3 ratio in $r d 3$ mice (Fig. $5 \mathrm{~b}$ ). This ratio of GCAP2 to GCAP2-P was very similar to the ratio reported for $\mathrm{EF}^{-} \mathrm{GCAP} 2$ mice $^{26}$, and indicates that GCAP2 in $r d 3$ mice is mostly in its phosphorylated $\mathrm{Ca}^{2+}$ -free state.

To gain insight into the mechanism by which $\mathrm{Ca}^{2+}$-free GCAP2 could contribute to the physiopathology of $r d 3$ mice, we searched for molecular targets of $\mathrm{Ca}^{2+}$-free GCAP2 in the retina. We performed pull-down assays with purified myristoylated recombinant bGCAP2 that was in vitro phosphorylated-or with its mock controlon Triton-X100 solubilized bovine retinas, under EGTA conditions (Methods section). Experiments were performed in triplicate. Bound proteins were identified by liquid chromatography and mass spectrometry (LC-MS/ MS) and subjected to label-free quantitative statistical analysis. For each identified protein (776 total proteins, Supplementary Table 1), the equation detailed in Methods section was used to determine its normalized spectral abundance factor (NSAF) in the GCAP2-P and the GCAP2 sample. The scatter plot in Fig. $5 \mathrm{c}$ presents the $\log _{2}$ (Mean NSAF $\mathrm{GCAP2-P}_{\text {-P }} /$ Mean NSAF $\mathrm{NCAP2}_{\text {2 }}$ ) on the $x$ axis, versus the $-10 \log (P$ value $)$ in the $y$-axis, considering threshold values of 1,35 and 5 for the $x$ - and $y$-axis, respectively. Proteins that showed an statistically significant preference for GCAP2-P are shown as red dots, while those with preference for unphosphorylated GCAP2 as blue dots (Fig. 5c).

The 14-3-3 proteins, known to interact with GCAP2$\mathrm{P}^{26}$, were identified with robust statistics as GCAP2-P binding proteins; as were proteins NDUFS5 (NADH dehydrogenase(ubiquinone) iron-sulfur protein 5), Ndel1 (nuclear distribution protein nude-like1), and RPL31 (60S ribosomal protein L31). On the other side, among the proteins with preference for unphosphorylated $\mathrm{Ca}^{2+}$-free GCAP2, were $\operatorname{HSP} 90(\alpha, \beta)$ and $\operatorname{HspB} 8$, chaperones that may be required to stabilize this unstable form of the protein, and superoxide dismutase 1 and peroxiredoxin-6, involved in maintaining the redox state of the cell.

RetGC1 was only identified in two out of three experiments, with $\leq 6$ spectral counts, and showed a slight preference for the unphosphorylated form of GCAP2 


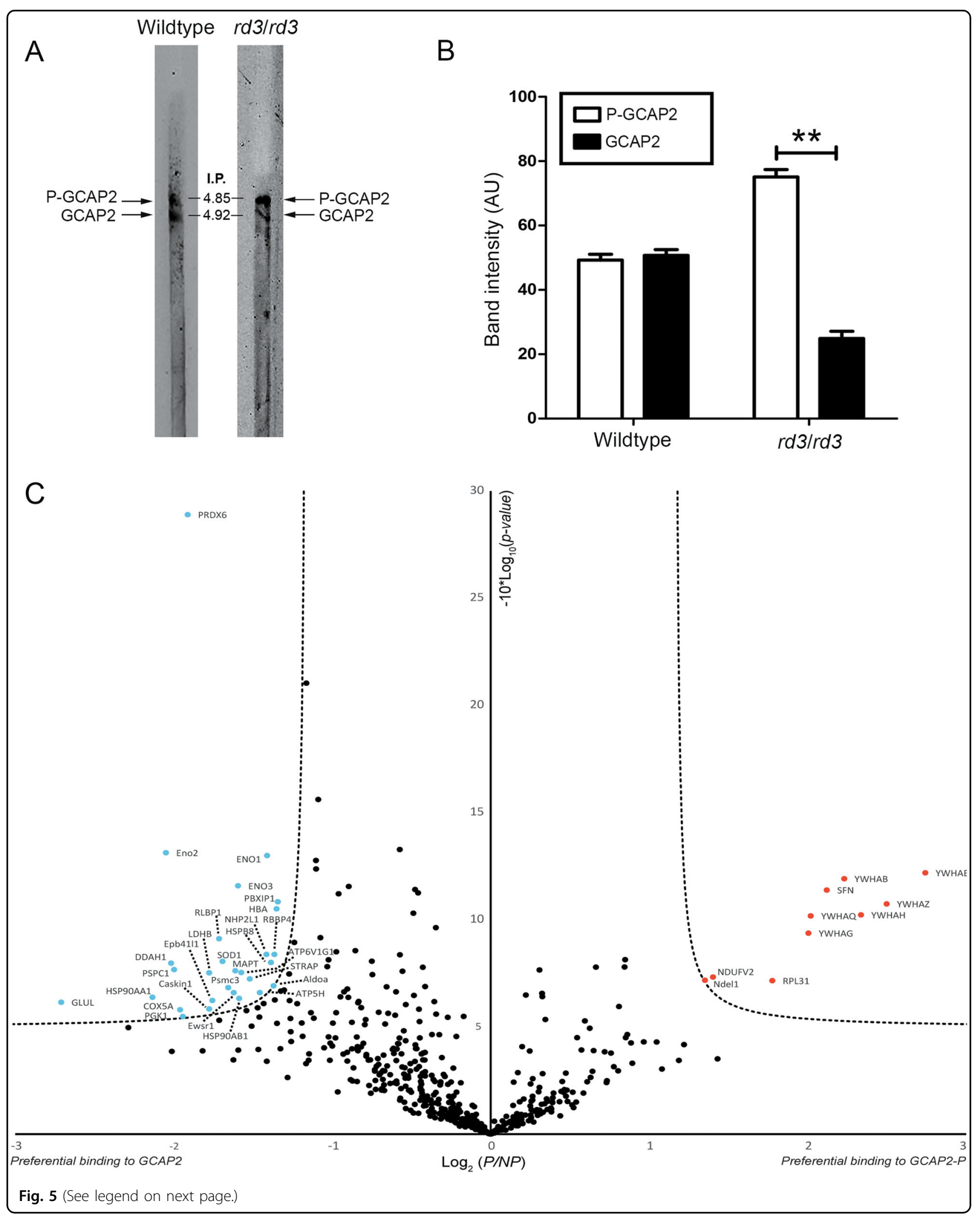


(see figure on previous page)

Fig. 5 GCAP2 in rd3/rd3 retinas is largely in its $\mathrm{Ca}^{2+}$-free-phosphorylated state, which is a target for 14-3-3 binding. a Isoelectric focusing (IEF) separation of retinal homogenates from wt and rd3/rd3 mice at p30 in linear pH 3-10 gradient gel strips. Following IEF, proteins were transferred to a nitrocellulose membrane and immunoblotted with anti-GCAP2 pAb. $\mathbf{b}$ The GCAP2-P to GCAP2 ratio was determined by densitometric analysis (mean \pm SEM) of three independent isoelectrofocusing experiments. Unpaired $t$-test (GCAP2 versus GCAP2-P in wt mice, $P=0.72$ ) and (GCAP2 versus GCAP2-P in $r d 3$ mice, $\left.P=0.0082^{* *}\right)$. $\mathbf{c}$ Label-free quantitative proteomic analysis to identify putative protein interactions of $C a^{2+}$-free GCAP2-P and GCAP2. Pull-down assays were performed on bovine retinal homogenates with purified myristoylated GCAP2 that was phosphorylated in vitro or a MOCK-phosphorylation control, under EGTA conditions. The volcano plot represents the statistical analysis of three independent pull-down assays. Log2 (P/NP) refers to Log2 (Mean NSAFGCAP2-P/Mean NSAFGCAP2), with NSAF being the normalized spectral abundance factor, see Methods section. The already reported 14-3-3 phosphobinding proteins (different isoforms) were clearly revealed as $\mathrm{Ca}^{2+}{ }_{-}$free GCAP2-P interactors, validating the assay. Other putative interactors identified with statistical significance are marked in red (GCAP2-P) and blue (GCAP2). The whole list of identified proteins is provided in Supplementary Table 1.

(Supplementary Table 1). However, it is well established that the RetGC-GCAPs interaction is very sensitive to detergents, and virtually impossible to detect in pull-down assays.

ER stress and mitochondrial swelling are prominent early signs of retinal degeneration in the $r d 3$ mice that are substantially rescued by GCAPs ablation

One early alteration that we observed in $r d 3$ retinas at p20 was rhodopsin mislocalization. Although rhodopsin transport is not affected by the lack of RD3 and rhodopsin antibodies largely stain the outer segment layer in $r d 3$ mice (e.g., Fig. 1), a number of photoreceptor cells showed rhodopsin perinuclear staining in any taken frame of the $r d 3$ outer retina at p20 (Fig. 6a). This was not observed in age-matching wt or $r d 3 / r d 3 \mathrm{GCAPs}^{-1-}$ mice (Fig. 6a). The number of cells per unit area that showed mislocalized rhodopsin in $r d 3$ mice was highest at p20 and diminished with age (Fig. 6b, c).

Because this signal could be reflecting rhodopsin retention at the ER due to ER dysfunction, we assessed ER stress by comparing the levels of ER stress marker C/EBP homologous protein (CHOP) in wt, $r d 3 / r d 3$ and $r d 3 / r d 3$ $\mathrm{GCAPs}^{-1-}$ mice. CHOP is a transcription factor that links severe ER impairment with the induction of apoptosis ${ }^{31}$. We observed a clear induction of CHOP expression in $r d 3$ mice at p20 (Fig. 6d, e), that was substantially prevented by GCAPs ablation (Fig. 6d, e).

Apoptotic cell death was assessed by evaluating caspase 3 activation (detection of the p17 large fragment from caspase 3 cleavage) and the cleavage of poly (ADP-ribose) polymerase PARP, a main target of caspases. Figure $6 \mathrm{~d}$, e shows activated p17 fragment of caspase 3 at a much higher level in $r d 3$ mice than in wt or $r d 3 / r d 3 \mathrm{GCAPs}^{-1-}$ mice, with statistical significance (experiment performed in triplicate). The extent of PARP1 cleavage in $r d 3$ mice versus wt and $r d 3 / r d 3 \mathrm{GCAPs}^{-1-}$ mice confirms the induction of apoptotic cell death in $r d 3$ mice at $\mathrm{p} 20$, that is partially rescued by GCAPs ablation.

Actually, one of the most prominent alterations in $r d 3$ mice at $\mathrm{p} 20-\mathrm{p} 26$ revealed by ultrastructural analysis was mitochondrial swelling, indicative of apoptosis. Figure 7 shows representative electron micrographs of $r d 3 / r d 3$ mice at p20-p26 (Fig. 7b, d), opposed to $r d 3 /$ wt heterozygous littermate controls (Fig. 7a, c). Retinas from $r d 3$ / $r d 3$ mice showed distinctive features like emerging vertical outer segment membrane discs (black arrows in Fig. $7 \mathrm{~b}, \mathrm{~d}$, and enlarged area in Fig. 7e); as well as disc structures that have been internalized at the inner segment (black arrowheads in Fig. 7f, g, h, k). The most prominent morphological alteration in $r d 3 / r d 3$ mice was mitochondrial swelling at the inner segment, noticeable at p20 at a fraction of cells (Fig. 7f, magnified at Fig. 7g), and at p26 at the majority of cells (Fig. 7i, j). This mitochondrial swelling preceded cell death.

Interestingly, the striking mitochondrial swelling in $r d 3$ photoreceptor cells (Fig. 7l) was greatly diminished in $r d 3 / r d 3 \mathrm{GCAPs}^{-1-}$ mice (Fig. $7 \mathrm{~m}$ ) when four animals of each genotype were compared (Fig. 7n).

Taken together, our results show that GCAPs induce the ER stress response in $r d 3$ mice, inducing $\mathrm{CHOP}$ expression and triggering apoptosis at a very early stage of the disease, and that GCAPs ablation substantially suppresses this induction and prevents photoreceptor cell death.

\section{Discussion}

We here show that the GCAP proteins play a central role in the physiopathology of blinding diseases associated to loss of functional RD3 (LCA12), by showing that GCAPs ablation substantially delays retinal degeneration in the $r d 3$ mouse model. While preservation of the retinal morphology is not accompanied by restoration of visual function, it is very revealing of the molecular mechanisms that link the lack of functional RD3 with photoreceptor cell death, and may assist at designing therapies to expand the window for gene therapy intervention in LCA12 patients.

We first confirmed all the previously reported manifestations of the phenotype of the $r d 3$ mice $^{15}$, with further attention to meaningful details. RetGC1 levels are drastically reduced in $r d 3$ retinas as reported, but can still be detected, and are estimated at $\sim 12 \%$ of the wild-type levels in $r d 3$ mice at p20 (Fig. 1). RetGC1 is retained at 

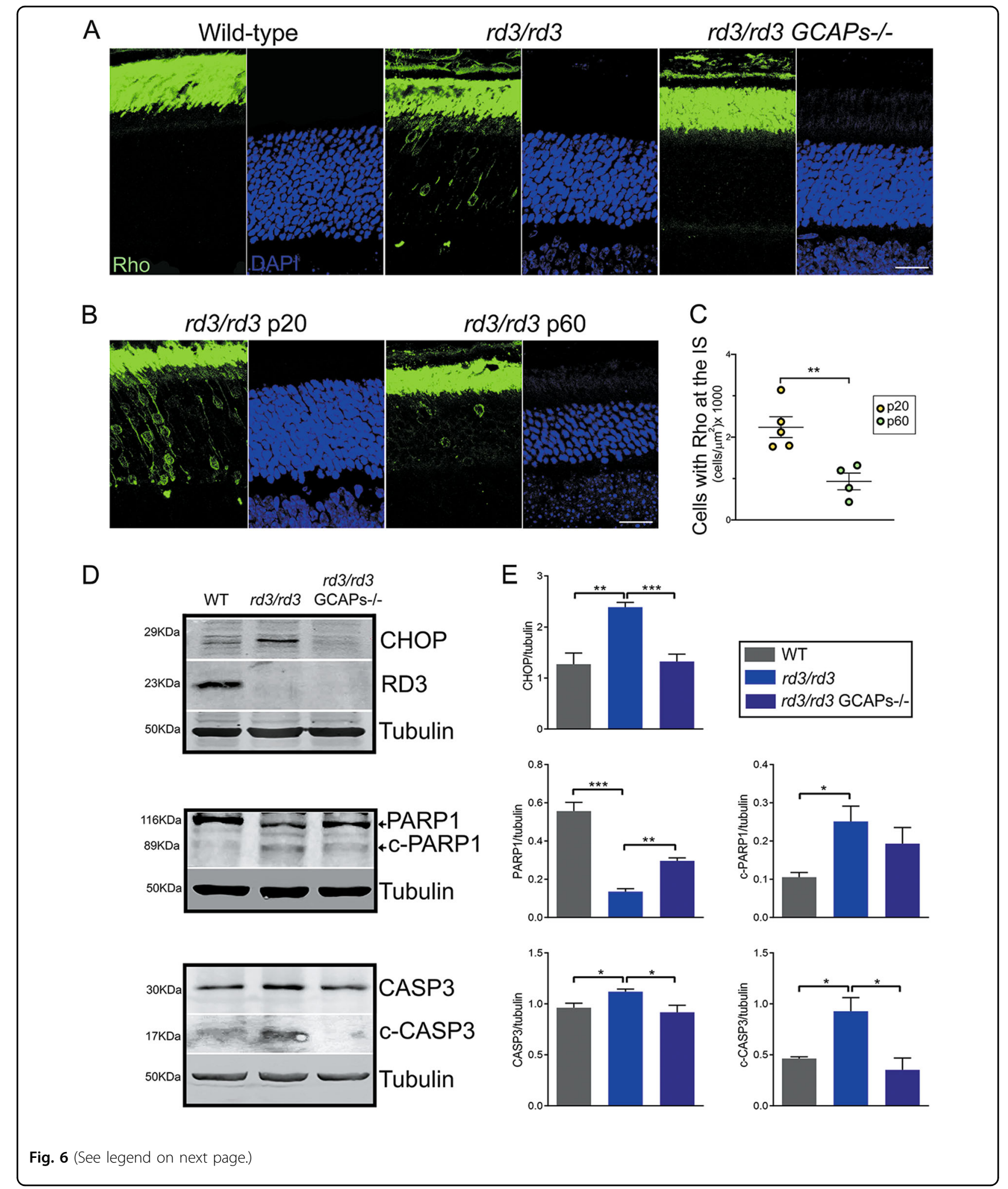

proximal cell compartments, mostly at the inner segment and perinuclear regions (Figs. 1d and 4). GCAP1 and GCAP2 levels are reduced in $r d 3$ mice to $\sim 37$ and $~ 42 \%$ of wild-type levels. Although mostly retained at the inner segment as previously reported ${ }^{15}$, traces of RetGC1, GCAP1, and GCAP2 are also observed at the outer 
(see figure on previous page)

Fig. 6 Rhodopsin mislocalization, ER stress, and apoptosis are early signs of retinal degeneration in rd3 mice that are palliated by GCAPs ablation. a Retinal sections from wt, rd3/rd3, and rd3/rd3 $\mathrm{GCAPs}^{-1-}$ mice at p20 stained with anti-rhodopsin antibody (green) and DAPI (blue). Rhodopsin mislocalization at the perinuclear region and proximal compartments is observed in a number of photoreceptor cells at any given frame of the outer retina in $r d 3 / r d 3$ mice at p20, but not in wt or $r d 3 / r d 3 \mathrm{GCAPs}^{-1-}$ mice this age. Scale bar $20 \mu \mathrm{m}$. b, c Representative images and quantification of cells that present rhodopsin mislocalization at p20 versus p60 in rd3 mice, expressed per unit area $(n=5 \mathrm{rd} 3 / \mathrm{rd} 3 \mathrm{mice}$ at p20; $n=4$ $r d 3 / r d 3$ mice at p60]. Unpaired $t$-test p20 versus p60, $P=0.0058^{* *}$ ). $\mathbf{d}$ Levels of $\mathrm{CHOP}$; full length and p17 kDa fragment of cleaved caspase 3 ; and full length and $89 \mathrm{kDa}$ fragment of cleaved PARP1 proteins in retinal extracts from wt, $r d 3 / r d 3$, and $r d 3 / r d 3 \mathrm{GCAPs}^{-1-}$ at p20. Note that the full-length casp3 and c-casp3 signals were obtained from different exposure conditions of the same membrane, given that c-casp3 represents a small percentage of full-length casp3. No RD3 protein was observed in $r d 3 / r d 3$ or $r d 3 / r d 3 \mathrm{GCAPs}^{-1-}$ extracts. e Six independent experiments were performed to determine CHOP expression levels (wt versus $r d 3 / r d 3, P=0.0012^{* *}$; and $r d 3 / r d 3$ versus $r d 3 / r d 3 \mathrm{GCAPs}^{-1-}, P=0.0001^{* * *}$ ). Three independent experiments were performed to determine PARP1 and c-PARP1 levels (PARP1: wt versus $r d 3, P=0.001^{* * *}$; and $r d 3 / r d 3$ versus $r d 3 / r d 3$ $\mathrm{GCAPs}^{-1-}, P=0.0018^{* *}$ ); (c-PARP1: wt versus $r d 3, P=0.026^{*}$; and $r d 3 / r d 3$ versus $\left.r d 3 / r d 3 \mathrm{GCAPs}^{-1-}, P=0.37 \mathrm{NS}\right)$. Three independent experiments were performed to determine casp3 and c-casp3 levels (casp3: wt versus rd3, $P=0.035^{*}$; and $r d 3 / r d 3$ versus $r d 3 / r_{d 3} \mathrm{GCAPs}^{-1-}, P=0.05^{*}$ ); (c-casp3: wt versus $r d 3, P=0.026^{*}$; and $r d 3 / r d 3$ versus $\left.r d 3 / r d 3 \mathrm{GCAPs}^{-1-}, P=0.031^{*}\right)$.

segment layer (Fig. 1d), explaining why $r d 3$ mice elicit bigger ERG responses than $r d 3 / r d 3 \mathrm{GCAPs}^{-1-}$ mice (Fig. 3).

The $r d 3$ strain of mice showed a fast rate of retinal degeneration, going from approximately ten rows of photoreceptor nuclei at p20 to approximately five rows at p44. GCAPs ablation substantially slowed down retinal degeneration, so that at 8 months of age $r d 3 / r d 3$ $\mathrm{GCAPs}^{-/-}$mice still retained five rows of photoreceptor nuclei. Therefore, the loss of RD3 still caused cell death in the absence of GCAPs, but at a substantially slower rate. We infer that: (i) the loss of RD3 causes an initial insult, with its origin in the closure of CNG-channels and the ensuing chronic decrease in $\left[\mathrm{Ca}^{2+}\right]_{\mathrm{i}}$; and (ii) the GCAP proteins mediate/amplify the response to this initial insult.

At a molecular level we show that $>75 \%$ of GCAP2 in $r d 3$ mice is phosphorylated and therefore in its $\mathrm{Ca}^{2+}$-free state, which is indicative of low $\left[\mathrm{Ca}^{2+}\right]_{\mathrm{i}}$ at $r d 3$ photoreceptor cell somas. Both GCAPs would therefore be in their $\mathrm{Ca}^{2+}$-free, guanylate cyclase activator state at photoreceptor cell somas of $r d 3$ mice, where they result in cellular damage. How would GCAPs induce damage in this context?

We envision two possible pathways, sketched in our proposed model in Fig. 8.

First, as proposed by Dizhoor et al. ${ }^{29} \mathrm{Ca}^{2+}$-free GCAPs could, in the absence of RD3, stimulate RetGCs and promote constitutive cGMP synthesis at the inner segment, where it would result in toxicity. Dizhoor's demonstration that RD3.GFP expressed as a transgene in rods localizes to the inner segment compartment ${ }^{29}$ supports RD3 proposed role of silencing RetGCs while at the inner segment ${ }^{25}$. Dizhoor et al. also bred the $r d 3$ mice to GCAPs $^{-1-}$ mice and reported the retinal morphological rescue, interpreting the outcome as a demonstration of the importance of cyclase silencing at the inner segment for photoreceptor viability. While we believe that other scenarios cannot be discarded at this point, we consider our data to be consistent with Dizhoor's interpretation.
We here show that the levels of RetGC in $r d 3$ mice are $\sim 12 \%$ of the wild-type levels, that are present at the inner segment layer. By showing that GCAP2 is mostly phosphorylated, we can infer that GCAPs are in their $\mathrm{Ca}^{2}$ ${ }^{+}$-free form. Although $75 \%$ of the GCAP2 present in $r d 3$ mice (reduced to $42 \%$ of GCAP2 wild-type levels) is phosphorylated and bound to 14-3-3 and therefore not free to bind the cyclase, there is still $~ 10 \%$ of GCAP2 (referred to wild-type GCAP2 levels) that could bind the cyclase and activate it in a constitutive manner. Constitutive synthesis of cGMP would therefore rely on $~ 12 \%$ of the wild type levels of RetGC and $~ 10 \%$ of GCAP2, which is apparently low. However, constitutive synthesis of cGMP at the inner segment compartment of cones has been shown to be very toxic and the basis of the physiopathology in mouse models of achromatopsia caused by null mutations in cone CNG-channel subunits CNGA3 and CNGB3. In these models, activation of cGMPdependent protein kinase (PKG) alters ER ionic homeostasis causing ER stress ${ }^{32-34}$. Actually, we here show that GCAPs mediate damage by activating ER stress-mediated apoptosis, by demonstrating CHOP induction as well as caspase 3 and PARP1 cleavage in $r d 3$ mice that are prevented in $r d 3 / r d 3$ GCAPs $^{-1-}$ mice (Fig. 6). Nevertheless, evidence of cGMP synthesis specifically at the inner segment compartment and/or PKG involvement is still missing in the $r d 3$ model and will require further investigation. An intriguing thought, assuming that preventing RetGC activity at the inner segment is critical for photoreceptor's viability, is that GCAP2 phosphorylation and 14-3-3 binding might serve as an additional mechanism to prevent cyclase activation in this compartment. Whether GCAP1 is phosphorylated is not known, and will require further investigation. However, it is GUCA1B gene encoding GCAP2 that was identified as a modifier gene of the $r d 3$ mouse phenotype ${ }^{27}$, and GCAP2 expression that was downregulated in $r d 3$ mice $^{35}$.

A second putative pathway of damage involves the conformational instability of $\mathrm{Ca}^{2+}$-free GCAP2, 


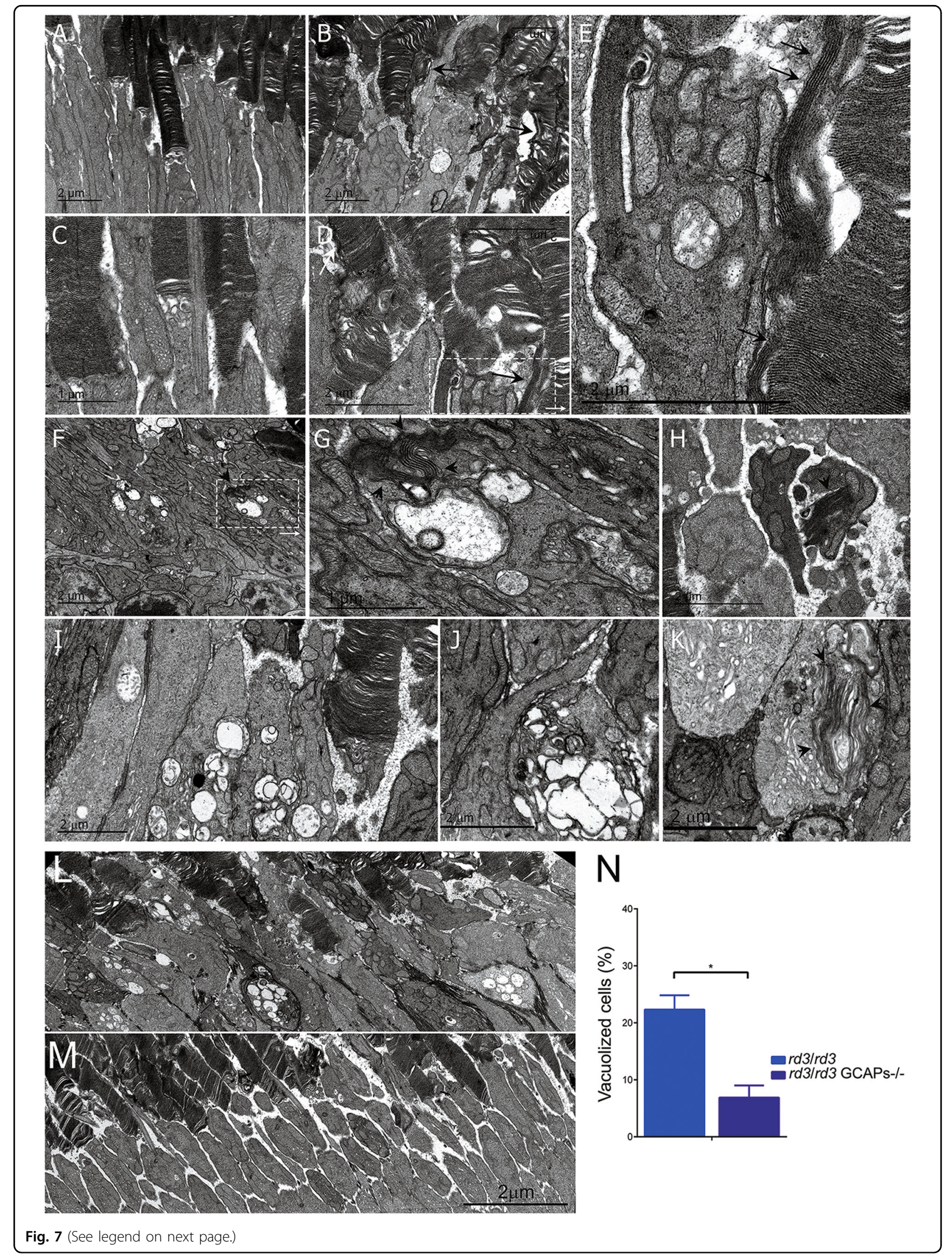


(see figure on previous page)

Fig. 7 Mitochondrial swelling is an early sign of retinal degeneration in $r d 3 / r d 3$ mice that is substantially prevented by GCAPs ablation. a-e Comparison of $r d 3 / r d 3$ retinas at p20 (b, d) versus $r d 3 /$ wt littermate controls $(\mathbf{a}, \mathbf{c})$. Retinas from $r d 3 / r d 3$ mice present distinctive features like emerging vertical outer segment membrane discs (black arrows in $\mathbf{b}$ and $\mathbf{d}$, and in the enlarged area in $\mathbf{e}$ ); as well as swelling mitochondria (arrowheads, $\mathbf{b}$ and $\mathbf{e}$ ). $\mathbf{f}, \mathbf{g}, \mathbf{i}, \mathbf{j}$ Mitochondrial swelling is a landmark ultrastructural alteration in $r d 3 / r d 3$ mice at early stages of retinal degeneration, as observed dramatically at a high number of photoreceptor cells at p26. $\mathbf{h}, \mathbf{k}$ Other striking alterations are the internalization at the inner segment of what appears to be stacks of outer segment disc membranes (black arrowheads). I, $\mathbf{m}, \mathbf{n}$ Mitochondrial swelling is substantially prevented by GCAPs ablation in the $r d 3$ mice, as observed by comparing a representative electron micrograph of retinal sections from $r d 3 / r d 3 \mathbf{I}$ and $r d 3 / r d 3$ GCAPs $-/-$ mice $\mathbf{m}$ at p26. Images are the result of fusing four transmission electron microscopy fields obtained at 10,000x magnification. The number of photoreceptor cells that present mitochondrial swelling is substantially reduced in $r d 3 / r d 3 \mathrm{GCAPs}^{-1-}$ mice versus $r d 3 / r d 3$ mice. $\mathbf{n}$ Four independent regions were analyzed per retina; and retinas were obtained from four mice of each genotype. Histograms represent the percentage of cells with presence of vacuoles, from the total number of cells. Unpaired $t$-test $\left(r d 3 / r d 3\right.$ versus $\left.r d 3 / r d 3 \mathrm{GCAPs}^{-1-}, P=0.019^{*}\right)$.

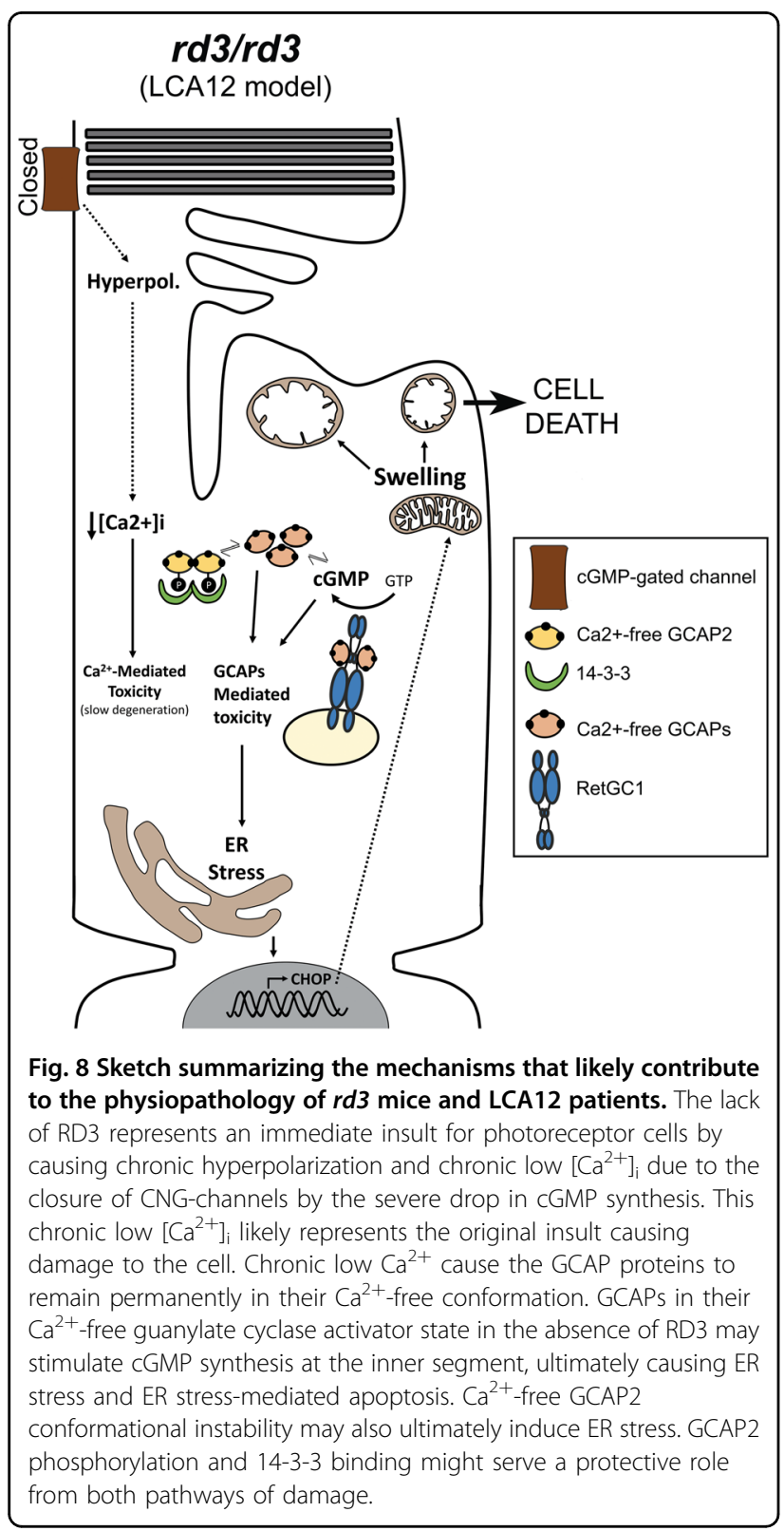

Fig. 8 Sketch summarizing the mechanisms that likely contribute to the physiopathology of $r d 3$ mice and LCA12 patients. The lack of RD3 represents an immediate insult for photoreceptor cells by

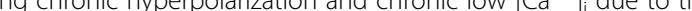
chronic low $\left[\mathrm{Ca}^{2+}\right]_{i}$ likely represents the original insult causing damage to the cell. Chronic low $\mathrm{Ca}^{2+}$ cause the GCAP proteins to remain permanently in their $\mathrm{Ca}^{2+}$-free conformation. GCAPs in their $\mathrm{Ca}^{2+}$-free guanylate cyclase activator state in the absence of RD3 may stimulate cGMP synthesis at the inner segment, ultimately causing ER stress and ER stress-mediated apoptosis. $\mathrm{Ca}^{2+}$-free GCAP2 phosphorylation and 14-3-3 binding might serve a protective role from both pathways of damage. manifested by its high tendency to aggregate when expressed in bacteria ${ }^{26}$. We have previously shown that a form of GCAP2 locked in its $\mathrm{Ca}^{2+}$-free form expressed as a transgene in rods is retained at the inner segment compartment by phosphorylation and 14-3-3 chaperone binding, leading to a fast retinal degeneration $^{26}$. EF ${ }^{-}$GCAP2 toxicity occurs in the presence of RD3 silencing the cyclase. One possibility would be that the $\mathrm{Ca}^{2+}$-free form of GCAP2 formed toxic protein oligomers, with 14-3-3 binding serving a protective role by preventing this formation. In this manner, GCAP2 could cause damage in a similar way as how $\alpha$-synuclein contributes to Parkinson's disease ${ }^{36,37}$. The instability of $\mathrm{Ca}^{2+}$-free GCAP2 is also reflected in its high affinity for the HSP90 dimer observed in pull-down assays (Fig. 5), that raises the possibility that $\mathrm{Ca}^{2+}$-free GCAP2 under chronic low $\left[\mathrm{Ca}^{2+}\right]_{\mathrm{i}}$ may trigger the heat shock response.

A few other proteins were selectively identified as putative interactors of GCAP2-P, like the cytoskeletal regulator Ndel1, nuclear-distribution gene $\mathrm{E}$ homolog like-1 protein, a modulator of dynein that has been involved in securing the selectivity of cargo delivered to axons $^{38}$, and at inhibiting primary cilia assembly in proliferating cells ${ }^{39}$. Ndel1 would be a putative candidate to mediate the morphological disc alterations observed in $r d 3$ mice. Future experiments will test this hypothesis, and aim at confirming other putative interactions.

Finally, by expressing RD3.V5 as a transgene in the rods of $r d 3$ mice, we report that RD3 localizes mainly to photoreceptor inner segments, although it also distributes to some extent to the outer segments (Fig. 4). The outer segment RD3 signal might not have been so apparent in the recent study of RD3.GFP localization in rods ${ }^{29}$ due to the protein modification by the much bigger tag. RD3 main localization to the inner segment provides some insight into the mechanisms underlying trafficking of the cyclase to the cilium. The cyclase is probably transported in two stages: a first stage, in which it is escorted and silenced by RD3 to the base of the connecting cilium; and a second, in which the GCAPs displace RD3 to bind the cyclase, previous to RetGC/GCAPs complex entry into 
the outer segment compartment. Future studies will be addressed at elucidating the mechanistic steps of this trafficking.

\section{Materials and methods Ethics statement}

Pertaining to animal research, this study was conducted in accordance with the Association for Research in Vision and Ophthalmology (ARVO) statement for the use of animals in ophthalmic and vision research and in compliance with acts 5/1995 and 214/1997 for the welfare of experimental animals of the autonomous community (Generalitat) of Catalonia; ref. \#9906, and approved by the ethics committee on animal experiments of the University of Barcelona, Bell 216/17, 217/17, and 218/17.

\section{Mice}

The B6.Cg-Rd3rd3/Boc strain of $r d 3$ mice used in this study were obtained from the Jackson's Laboratories (JAX Stock \#8627 Maine, USA) as heterozygous wt $/ r d 3$ mice $^{13}$. These mice present a point mutation after residue 106 $(\mathrm{C} \rightarrow \mathrm{T})$ that results in a premature stop codon after residue 106. The $r d 3$ mutation results in expression of a truncated form of the RD3 protein that is rapidly degra$\operatorname{ded}^{14}$. Heterozygous animals were bred in order to obtain homozygous $r d 3 / r d 3$ mice. Mice were genotyped by realtime polymerase chain reaction (RT-PCR) by making use of the TaqMan ${ }^{\circledR}$ SNP genotyping assay (Life Technologies, Carlsbad, USA). For that purpose, forward and reverse primers were designed to amplify a fragment of 68 bp from the $R d 3$ locus of genomic DNA that encompasses the $r d 3$ mutation (Fw: 5'-CTGGAGACGC TCATGATGGA-3'; and Rv: 5'-CGACGCTCCCTCTG TTGT- $3^{\prime}$ ) and primer probes were designed to hybridize with either the amplified wild-type allele (VIC-5'-CT CTCTCATCTGCCCAGCC-3') or knock-out allele (FAM-5'-CTCTCTCATCTACCCAGCC-3'). RT-PCR was performed in $25 \mu \mathrm{l}$ reactions containing $12.5 \mu \mathrm{l}$ TaqMan universal master Mix (Life Technologies); $300 \mathrm{nM}$ each forward/reverse primer; $250 \mathrm{nM}$ of each primer probe, and $20 \mathrm{ng}$ of genomic DNA obtained from digested mouse tails (Nucleospin ${ }^{\circledR}$ Tissue, Macherey-Nagel, Düren, Germany). After $10 \mathrm{~min}$ incubation at $95^{\circ} \mathrm{C}$, thermal cycling was performed on the StepOne Real-time PCR System (Thermo Fisher Scientific, Waltham, Massachusetts) and consisted of 40 cycles $\left(95^{\circ} \mathrm{C}\right.$ for $15 \mathrm{~s} ; 60^{\circ} \mathrm{C}$ for $1 \mathrm{~min})$. End-point allelic discrimination genotyping was assessed by inspecting the fluorescence plots for the wild type versus mutated probe.

To obtain mice expressing the $r d 3$ mutation to homozygosis in the $\mathrm{GCAPs}^{-1-}$ background, $r d 3 / r d 3$ mice were bred to $\mathrm{GCAPs}^{-1-}$ mice. GCAPs ${ }^{-1-}$ mice lack GCAP1 and GCAP2 expression, and their phenotype has been described $^{40}$.

\section{Antibodies}

Anti-GCAP1 and anti-GCAP2 polyclonal antibodies have been previously described ${ }^{22}$. The polyclonal antibodies against RetGC1 and RD3 were generated in rabbit against $\mathrm{C}$-terminal peptides corresponding to the last 21aa of murine RetGC1 and the last 16aa of murine RD3. Peptides were conjugated to keyhole limpet hemocyanin carrier protein (Imject maleimide activated carrier protein spin kit, Thermo Fisher Scientific) for inoculation in rabbits. A 90-day, three antigen-injection protocol was followed. Serum from immunized rabbits was purified by affinity chromatography by using the immunizing peptide covalently coupled to an agarose column by $-\mathrm{SH}$ chemistry (Sulfolink immobilization kit for peptides, Thermo Fisher Scientific). The specificity of the antibodies is shown by Western blot analysis of whole retinal extracts in Supplementary Fig. 1.

\section{Specimen preparation for light and electron microscopy}

Mice of the indicated genotypes were reared under standard cyclic light ( $12 \mathrm{~h}$ dark: $12 \mathrm{~h}$ light) and sacrificed by cervical dislocation. The vertical meridian of the eye was marked at the top for orientation purposes. The eye was enucleated, punctured, and immediately submerged in $2 \%$ paraformaldehyde, and $2.5 \%$ glutaraldehyde in $0.1 \mathrm{M}$ cacodylate buffer $\mathrm{pH} 7.2$ for $5 \mathrm{~min}$. The cornea was excised and fixation was allowed to proceed for $1 \mathrm{~h}$, before removal of the lense and further fixation of the eye cup for $12 \mathrm{~h}$ at $4{ }^{\circ} \mathrm{C}$. Eye cups were washed with $0.1 \mathrm{M}$ cacodylate buffer and fixed with $1 \%$ osmium tetroxide in $0.1 \mathrm{M}$ cacodylate buffer for $2 \mathrm{~h}$ at room temperature. Specimens were dehydrated in ethanol $(30-100 \%)$ or acetone, infiltrated with propylene oxide, and embedded in Epoxi embedding medium (Fluka Analytical, Munich, Germany). Retinal sections for histological analysis by light microscopy morphometry measurements were obtained with a Reichert Ultracut S ultramicrotome (Leica, Wetzlar, Germany) at 1- $\mu \mathrm{m}$ thickness and contrasted with Richardson's stain $(0.5 \%$ methylene blue, $0.5 \%$ Azine II, and $0.5 \%$ borax in $\mathrm{dH}_{2} \mathrm{O}$ ). For transmission electron microscopy analysis, ultrathin sections were obtained (see below).

\section{Retinal morphometry analysis}

For morphometrical analysis, measurements of ONL thickness were taken on $1-\mu \mathrm{m}$ sections at the vertical meridian of the eye that encompassed the optic nerve. Overlapping frames at $20 \times$ magnification were acquired covering the whole section with a Zeiss Axio Zoom. V16 stereo microscope (Zeiss, Oberkochen, Germany). An integrated image of the whole retinal section was assembled with the HUGIN fusion software. Measurements of ONL thickness were taken at $200-\mu \mathrm{m}$ intervals from the optic nerve (12 divisions in the superior retina, and 10 divisions in the inferior retina). For each 
morphometry analysis a minimum of four mice per genotype were used at indicated ages. Error bars represent the standard error of the mean (SEM).

\section{Ultrathin sectioning and image acquisition at the transmission electron microscope}

Ultrathin sections $(70-90 \mathrm{~nm})$ were obtained with a Reichert Ultracut $S$ ultramicrotome (Leica), collected on 200 mesh copper grids, counterstained by heavy metal staining ( $2 \%$ uranyl acetate in $50 \%$ ethanol for $30 \mathrm{~min}$ ), and contrasted with $2 \%$ lead citrate for $10 \mathrm{~min}$. Ultrathin sections were analyzed in a JEOL 1010 transmission electron microscope and images acquired with a Bioscan Gatan wide angle slow scan CCD camera.

\section{Immunofluorescence analysis in fixed tissue}

For immunofluorescence analysis, eye cups were fixed in $4 \%$ paraformaldehyde, $0.02 \%$ glutaraldehyde in phosphate-buffered saline (PBS), $\mathrm{pH}=7.4$ for $2 \mathrm{~h}$ at room temperature. Eye cups were infiltrated in acrylamide $(8.4 \%$ acrylamide, $0.014 \%$ bisacrylamide in $\mathrm{PBS} \mathrm{pH} 7.4$ ) overnight at $4{ }^{\circ} \mathrm{C}$. Acrylamide polymerization was induced and eye cup acrylamide blocks immediately frozen in O.C.T. compound (Tissue-Tek, Electron microscopy Sciences, Hatfield, PA) using liquid nitrogen. Cryosections were obtained at $18-\mu \mathrm{m}$ thickness with a CM15105 Leica Cryostat (Leica Microsystems, Wetzlar, Germany). Immunolocalization of GCAP1 and GCAP2 required an antigen retrieval protocol, consistent on incubation with proteinase $\mathrm{K}(0.05 \mathrm{mg} / \mathrm{ml}$ in PBS) for $2 \mathrm{~min}$, followed by a $10 \mathrm{~s}$ heating shock at $70^{\circ} \mathrm{C}$. Sections were incubated with blocking solution (3\% normal goat serum, 1\% bovine serum albumin (BSA), 0.3\% Triton-X100 in PBS pH7.4) for $1 \mathrm{~h}$; first antibody in dilution buffer (3\% normal goat serum, $0.4 \%$ BSA, $0.1 \%$ Triton-X100 in PBS pH 7.4) for $16 \mathrm{~h}$ at $4{ }^{\circ} \mathrm{C}$; and secondary antibody $(1.5 \mathrm{~h}$ at room temperature), and fixed with $4 \%$ paraformaldehyde prior to being mounted with Mowiol (Calbiochem \#475904, San Diego, CA, USA). Antibodies used were anti-RetGC1 pAb; anti-GCAP1 pAb; anti-GCAP2 pAb; anti-rhodopsin mAb 1D4; anti-PNA-647 (\# L32460, Thermo Fisher Scientific); anti-rabbit Alexa Fluor 488 (Thermo Fisher Scientific A-11034, Walthman, MA, USA); and anti-mouse Alexa Fluor 555 (Thermo Fisher Scientific \#A-32727). Samples were mounted on $0.13-0.16 \mathrm{~mm}$ thick cover glasses.

\section{Confocal microscopy and data analysis}

Confocal microscopy images were acquired at a confocal laser scanning microscope Zeiss LSM 880 equipped with one GaAsP detector, with a $63 \times / 1.4$ NA oil objective. For localization of RetGC and GCAPs in Figs. 1 and 2, spectral bands were set to $493-550 \mathrm{~nm}$ for the 488 channel, $566-638 \mathrm{~nm}$ for the 555 channel, and to
$638-755 \mathrm{~nm}$ for the 647 channel. The $Z$-stacks covered $16 \mu \mathrm{m}$ of tissue with a $368 \mathrm{~nm}$ step size ( 40 planes/ stack). The image acquisition settings provided a pixel size of about $0.132 \times 0.132 \mu \mathrm{m}$ in $1024 \times 1024$ images.

\section{Western blot}

Retinas (at least $n=3$ per condition) were homogenized in Laemmli sodium dodecyl sulfate (SDS) buffer with $1 \mathrm{mM}$ phenylmethylsulfonyl fluoride (PMSF), and protease cocktail inhibitor (Complete mini EDTA-free, Roche). Samples were boiled for $10 \mathrm{~min}$ at $95^{\circ} \mathrm{C}$, and fractions corresponding to one tenth of a retina were resolved by 12 or $16 \%$ SDS-polyacrylamide gel electrophoresis. Proteins were transferred to nitrocellulose membranes $(0.2 \mu \mathrm{m}$ nitrocellulose, Bio-Rad, Hercules, CA, USA). Membranes were blocked for $1 \mathrm{~h}$ at room temperature with $5 \%$ non-fat dry milk in TBST and then were incubated overnight at $4{ }^{\circ} \mathrm{C}$ with custom polyclonal antibodies to RetGC1, RD3, GCAP1, and GCAP2, and antibodies anti-CHOP (Cell Signaling L63F7); antiCaspase 3 (Cell Signaling 9662); anti-PARP1 (Cell Signaling 9542); goat anti-rabbit IgG (Heavy and Light chains) antibody Dylight ${ }^{\mathrm{TM}} 800$ conjugated (Rockland \#611-145-002, Pottstown, PA, USA); goat anti-mouse IgG (H\&L) antibody Dylight ${ }^{\mathrm{TM}} 680$ conjugated (Rockland \#610-144-002-0.5); and donkey anti-goat conjugated to Horseradish Peroxidase (HRP) was from Thermo Fisher (86326). Detection was performed in an Odyssey Scanner (LI-COR Biosciences, Lincoln, Nebraska) or ImageQuant $^{\mathrm{TM}}$ LAS500 (Ge Healthcare, Chicago, Illinois) image acquisition system. Band densitometric analysis was performed using the Fiji (Image J) software, and band intensity analysis presented in histograms always reflect band intensity of the protein of interest normalized by the intensity of tubulin in the loading control.

\section{Isoelectric focusing separation of murine retinal homogenates}

Retinas from wt and $r d 3 / r d 3$ mice were dissected at $\mathrm{p} 21$, at an early onset of retinal degeneration of $r d 3$ mice. Retinas were homogenized in homogenization buffer with phosphatase inhibitors [20 mM Hepes, $115 \mathrm{mM} \mathrm{KCl}$, $10 \mathrm{mM} \mathrm{NaCl}, 10 \mathrm{mM} \mathrm{MgCl}_{2}, 50 \mathrm{mM} \mathrm{NaF}, 5 \mathrm{mM}$ $\beta$-glycerophosphate, $1 \mathrm{mM}$ PMSF, and a protease cocktail inhibitor (Complete mini EDTA-free, Roche, Basel, Switzerland); $\mathrm{pH}$ 7.4]. Samples were centrifuged at $13,200 \mathrm{rpm}, 4^{\circ} \mathrm{C}$ for $30 \mathrm{~min}$, and supernatant fractions were kept. An aliquot was taken at this point for protein determination (BCA kit, Thermo Fisher Scientific). Protein material in supernatant fractions was precipitated by addition of three volumes of ice-chilled trichloroacetic acid (TCA)-acetone (13.3\% w/v trichloroacetic acid in acetone, with dithiothreitol (DTT) to $20 \mathrm{mM}$ final concentration); equilibration of samples to $-20^{\circ} \mathrm{C}$ for $72 \mathrm{~h}$; 
and centrifugation at $13,000 \times g$ for $1 \mathrm{~h}$ at $4{ }^{\circ} \mathrm{C}$. Protein pellets were washed twice with cold $20 \mathrm{mM}$ DTT in acetone; and allowed to air-dry for $10 \mathrm{~min}$. Samples were dissolved in urea/thiourea/CHAPS/DTT (7 M urea, $2 \mathrm{M}$ thiourea, $40 \mathrm{mM}$ DTT, 4\% CHAPS, and 2\% IPG buffer $\mathrm{pH}$ 3-10) to ensure complete reduction, denaturing, and solubilization of proteins in the samples.

Samples were kept at $-80^{\circ} \mathrm{C}$ until use. For isoelectric focusing (IEF) separation, gel strips with a preformed linear $\mathrm{pH}$ gradient of $\mathrm{pH}$ 3-10 (prehydrated IPG Immobiline (TM) DryStrips pH 3-10, $18 \mathrm{~cm}$, GE Healthcare) were used. Threefold more sample was loaded for $r d 3 / r d 3$ retinas than wt retinas in order to equilibrate the GCAP2 signal. IEF separation was conducted on an Ettan IPGphor3 system (GE Healthcare), following a $500 \mathrm{~V}$ step for $1 \mathrm{~h}$, a gradient to $1000 \mathrm{~V}$ for $1 \mathrm{~h}$, a gradient to $10,000 \mathrm{~V}$ for $3 \mathrm{~h}$, and a $10,000 \mathrm{~V}$ step for $3 \mathrm{~h}$. Gel strips were incubated in transfer buffer for $15 \mathrm{~min}$, and proteins were transferred to nitrocellulose membranes by capillary action. GCAP2 was immunoblotted with anti-GCAP2 pAb and goat anti-rabbit IgG (Heavy and Light chains) antibody Dylight ${ }^{\mathrm{TM}}$ 800. Bands were visualized at an Odyssey scanner (LI-COR), and densitometry analysis was performed with the Fiji (ImageJ) software.

\section{Expression, purification, and in vitro phosphorylation of myristoylated GCAP2 for pull-down assays}

Myristoylated GCAP2 expression was induced in Escherichia coli BL21(DE3) cells transformed with pET15b-bGCAP2 and the pBB131 plasmid encoding Nmyristoyl transferase (a gift from Dr. J. Gordon, Washington University School of Medicine, Missouri, USA). Free myristic acid was added to $50 \mu \mathrm{g} / \mathrm{ml}$ to the cell culture and expression was induced for $4 \mathrm{~h}$ at $37^{\circ} \mathrm{C}$. bGCAP2 protein, was recovered from solubilized inclusion bodies and purified by on-column refolding using immobilized metal affinity chromatography (IMAC) on a Nickel-NTA [Nickel bound to agarose beads by chelation using nitrilotriacetic acid] as previously described ${ }^{26}$.

To obtain phosphorylated bGCAP2 for pull-down assays, in vitro phosphorylation reactions were performed with protein kinase G (PKGI $\alpha$, Calbiochem, Billerica, MA, USA). Each $50 \mu \mathrm{l}$ reaction contained $30 \mathrm{mM}$ Tris- $\mathrm{HCl} \mathrm{pH}$ 7.5, $5 \mathrm{mM} \mathrm{MgCl}, 5 \mathrm{mM}$ sodium phosphate buffer pH 7.5, 6 mM DTT, 2 mM EGTA, $10 \mu \mathrm{M}$ ATP, and $500 \mu \mathrm{M}$ cGMP, with $10 \mu \mathrm{g}$ of bGCAP2 in the presence or absence of purified PKGI $\alpha$ (100 units) to obtain phosphorylated GCAP2 (GCAP2-P) and the mock-control (GCAP2). Phosphorylation reactions were allowed to proceed for $2 \mathrm{~h}$ at $30^{\circ} \mathrm{C}$, and GCAP2 and GCAP2-P were covalently linked to Epoxi-magnetic beads (Life Technologies, Carlsbad, CA, USA). GCAP2- or GCAP2-Pbeads were then incubated with bovine retinal homogenates obtained by homogenization of fresh bovine retinas in binding buffer $(10 \mathrm{mM}$ HEPES, $135 \mathrm{mM} \mathrm{NaCl}$, $5 \mathrm{mM} \quad \mathrm{KCl}, 1 \mathrm{mM}$ PMSF, $1 \mathrm{mM} \mathrm{NaF}, 1 \mathrm{mM}$ $\beta$-mercaptoethanol, 1\% Triton X-100, $4 \mathrm{mM}$ EGTA, 2 mM EDTA, and Complete Mini protease inhibitors, $\mathrm{pH}$ 7.4). After $1 \mathrm{~h}$ incubation at room temperature, beads were washed and bound proteins were eluted under acidic conditions. Magnetic beads were extensively washed, and bound material was eluted in $0.2 \mathrm{M}$ glycine $\mathrm{pH} 2.5$ and immediately neutralized. Proteins in the bound fraction were identified by LC-MS/MS. The experiment included three biological replicates.

\section{LC-MS/MS}

Samples were reduced with $10 \mathrm{mM}$ DTT at $60^{\circ} \mathrm{C}$ for $30 \mathrm{~min}$, and alkylated with $55 \mathrm{mM}$ iodoacetamide for $30 \mathrm{~min}$ at room temperature. Samples were precipitated with $10 \%$ TCA. Pellets were dissolved in $2 \mu \mathrm{l}$ of $8 \mathrm{M}$ urea and brought to a final volume of $10 \mu \mathrm{l}$ with $25 \mathrm{mM}$ ammonium bicarbonate. Samples were digested with sequencing grade trypsin in $25 \mathrm{mM}$ ammonium bicarbonate for $12 \mathrm{~h}$. For LC-MS/MS, samples were resuspended in $0.1 \%$ formic acid and injected into a series Proxeon LC nanoEASY system (Thermo Fisher Scientific) coupled to a LTQ-Velos Orbitrap (Thermo Fisher Scientific). The resulting mass spectral peak lists were searched with the Sequest search engine (v.2.1.04, Matrix Sciences, London, UK) against the merged BOVIN-MOUSE UP SP r 2011-1. fasta sequence library. For database searching, raw mass spectrometry files were submitted to the in-house MOUSE-BOVIN_UP_SP_r_2014-5.fasta Swiss-Prot database (released February 2014; 22460 protein entries) using SEQUEST version 28.0 (Thermo Fisher Scientific). The criteria used to accept identification included a minimum of two peptides matched per protein, with a false discovery rate of $1 \%$. All proteins were treated as ungrouped.

\section{Characterizing differential protein interactions of GCAP2-P and GCAP2}

For label-free quantitative proteomic analysis of proteins identified with GCAP2-P versus GCAP2, we first filtered the protein lists to remove any duplications resulting from the use of bovine and mouse fasta sequence libraries. Only those proteins unequivocally assigned by at least a unique peptide were retained. For each protein identified the NSAF was calculated with the following equation:

$$
\mathrm{NSAF}_{k}=\frac{\left(\mathrm{SpC}_{k}+1\right) / L_{k}}{\sum_{i=0}^{n}\left(\mathrm{SpC}_{i}+1\right) / L_{i}}
$$

where $\mathrm{NSAF}_{k}$ is the Normalized Spectral Abundance Factor ${ }^{41}$ for a given protein $\mathrm{k} ; \mathrm{SpC}_{k}$ is the Spectral Count for protein $k, L_{k}$ is the length of the protein in number of amino acids; and the denominator is the summation of 
the NSAFs of all identified proteins in that sample. This expression corrects for differences in sampling depth between both conditions assayed, and avoids the discontinuity seen in simple count ratios when a protein shows spectral count $=0$ in one of the samples.

Mean NSAF values were then calculated from triplicate biological samples, followed by a $t$-test comparison (two tails, unequal variance). To obtain the volcano plot, the $\log _{2} \operatorname{Mean}_{P} \operatorname{Mean}_{N P} \quad$ was plotted in the $x$-axis; and the $-10 \log (p$ value $)$ from the $t$-test was plotted in the $y$-axis, with $\mathrm{Mean}_{P}$ referring to Mean $\mathrm{NSAF}_{\mathrm{GCAP2}-\mathrm{P}}$, and $\mathrm{Mean}_{N P}$ referring to Mean $\mathrm{NSAF}_{\mathrm{GCAP2}}$. Threshold curves for the volcano plot were obtained by fitting values to

$$
f(x)=\frac{1}{x^{2}-n}+m
$$

were $n$ is the value of the $\log _{2} \frac{\operatorname{Mean}_{P}}{\operatorname{Mean}_{N P}}$ ratio threshold and $m$ is the $-10 \log (p$ value $)$ threshold. $m$ and $n$ values were fixed to 5 and 1.35 respectively. (Notes: taking $a \equiv$ $\log _{2}\left(\frac{P}{N P}\right) \quad$ and $b \equiv-10 \log (p-$ value $)$, the proteins passing the thresholds are those proteins that: $a<-\sqrt{n}$ and $b>f(x)$ for the negative side; and $a>\sqrt{n}$ and $b>f(x)$, for the positive side.

\section{Electroretinography}

A total of 4-7 mice were tested for each animal group. Dark-adapted $(>12 \mathrm{~h})$ animals were anesthetized with an intraperitoneal injection of ketamine $(70 \mathrm{mg} / \mathrm{kg}$; Ketalar, Parke-Davis, Wellington, New Zealand) and xylazine (7 mg/kg; Rompun, Bayer, Leverkusen, Germany) in saline solution $(\mathrm{NaCl} 0.9 \%)$ and pupils were dilated with one drop of $1 \%$ tropicamide. A corneal electrode was used to record ERGs from right eyes (Burian-Allen, Hansen Ophthalmic Development Lab, Coralville, IA). Electrode was placed in the visual axis $1-2 \mathrm{~mm}$ from the cornea and a drop of 2\% methyl-cellulose (Methocel, Ciba Vision, Hetlingen, Switzerland) was dropped between cornea and electrode. Mice were maintained for $>5 \mathrm{~min}$ in absolute darkness before the recordings. Mouse temperature during the recording was maintained at $37^{\circ} \mathrm{C}$ with a liquid heating pad. Full-field flash ERG responses were recorded with the retina illuminated with a LED-driven Ganzfeld dome. A series of light flashes of increasing intensity (from 0.001 to $10 \mathrm{~cd} / \mathrm{s} / \mathrm{m}^{2}$ ) were averaged both in scotopic and photopic conditions. Photopic cone responses were recorded following $5 \mathrm{~min}$ of light adaptation with a background white light $\left(50 \mathrm{~cd} / \mathrm{m}^{2}\right)$. Light intensity was controlled for each animal group (Mavo-Monitor USB, Gossen, Germany). Recorded electrophysiological responses were amplified, filtered (CP511 AC amplifier; Grass Instruments, Quincy, MA), and digitalized (ADInstruments Ltd, Oxfordshire, UK). The recording process was controlled with Scope version 3.8.1 software (Power Lab, ADInstruments Ltd). The stimulation protocols were designed according to the International Society for Clinical Electrophysiology of Vision.

\section{Generation of pRho-mRd3.V5-dsRed expression vector and in vivo DNA electroporation}

The expression vector used for in vivo DNA electroporation was based on the plasmid pRho-DsRed. pRhoDsRed was a gift from Connie Cepko (Addgene plasmid\#11156; $\quad$ http://n2t.net/addgene:11156;RRID: Addgene_11156) ${ }^{42}$. This plasmid contains the $2.2 \mathrm{~kb}-$ version of the rod opsin promoter from Bos taurus ${ }^{43}$; a multicloning site; a Kozak sequence; the DsRed2 reporter gene; and the $\beta$-globin poly $(\mathrm{A})$ signal $^{42}$. To make pRhomRD3.V5-DsRed, murine $r d 3$ cDNA was amplified by PCR with a forward primer that introduced an XbaI restriction site and the reverse primer introducing the V5 epitope in frame with $\mathrm{RD} 3 \mathrm{COOH}$-terminal sequence, followed by an EcoRI restriction site. The mRD3.V5 DNA was inserted in the XbaI and EcoRI sites of pRho-DsRed, and the resulting expression vector was verified by sequencing. For in vivo electroporation, pRho-mRd3.V5dsRed vector was amplified with the pureLinkTM Expi Endotoxin-Free Mega Plasmid Purification Kit (Invitrogen, Carlsbad, California).

In vivo DNA electroporation in the retina following DNA injection in the subretinal space was performed as originally described ${ }^{42}$ with minor modifications. A DNA solution $(6 \mu \mathrm{g} / \mu \mathrm{l})$ was prepared by mixing pRhoDsRed and pRho-mRD3.V5-DsRed at a molar ratio of $1: 4$ in phosphate saline buffer with $0.1 \% \mathrm{v}-\mathrm{v}$ fast green. Even though pRho-mRD3.V5-DsRed expressed dsRed, we found the levels of expression too low for detection of the eye injected area at the fluorescence dissection scope. Therefore pRho-DsRed was coinjected with pRho-mRD3.V5-DsRed. Pups were injected the day they were born at the subretinal space, with $0.2-0.5 \mu \mathrm{l}$ of DNA by using a Hamilton syringe with a blunt 30 gauge needle under a dissecting microscope (Zeiss KL1500LCD. Stemi2000, Germany). Tweezer-type electrodes were placed softly holding the head of the pup, and five $80 \mathrm{~V}$ square pulses of $50 \mathrm{~ms}$ duration with $950 \mathrm{~ms}$ intervals were applied using a CUY21 electroporator (Nepagene, Chiba, Japan). Electroporated eyes were processed at p20-p25 for immunofluorescence localization analysis as described above. Antibodies were anti-RetGC1 pAb and the anti-V5 mAb (2F11F7, Invitrogen) by secondary antibodies $\alpha$-rabbit Alexa Fluor 488 (Life Technologies) and $\alpha$-mouse Alexa Fluor 647 (Life Technologies) both at 1:500 for $1.5 \mathrm{~h}$ at room temperature. The image has been acquired with a LEICA SP5 microscope using a $63 \times 1.4$ NA oil objective. The pixel and step sizes are $100 \mathrm{~nm}$ and $198 \mathrm{~nm}$ 
respectively providing an effective image volume of $131 \mu \mathrm{m} \times 131 \mu \mathrm{m} \times 9.5 \mu \mathrm{m}$. Two Hybrid detectors in photon counting mode and a photomultiplier tube (PMT) have been used to acquire the different channels. The spectral configuration for the channel 1 used a $488 \mathrm{~nm}$ laser line and an emission window from 498 to $535 \mathrm{~nm}$. The channel 2 used the $633 \mathrm{~nm}$ laser line and an emission window between 642 and $722 \mathrm{~nm}$. Finally, the channel 3 used the $543 \mathrm{~nm}$ laser line with the emission window set between 551 and $616 \mathrm{~nm}$.

\begin{abstract}
Acknowledgements
We acknowledge the assistance of Dr. A. Gimeno and L. Gómez-Segura at the Vivarium facility with antibody generation in rabbits and with animal procedures. We kindly acknowledge the excellent technical assistance of Dr. Benjamín Torrejón with image acquisition at the Leica TCS-SL at the CCiT-UB. We thank Dr. Cristina Muñoz for her advice on ER stress analysis. J.A. and P.L. acknowledge financial support from the Spanish Ministry of Economy and Competitiveness through the "Severo Ochoa" program for Centres of Excellence in R\&D (SEV-2015-0522), from Fundació Privada Cellex, Fundación Mig-Puig, from Generalitat de Catalunya through the CERCA program, and Laser lab Europe (No. 654148). Pdl.V. was supported by a grant from the Spanish Instituto de Salud Carlos III [ISCIII] (PI18/00754). A.M. acknowledges funding from the Spanish Ministry of Economy and Competitiveness (MINECO): BFU2016-80583-R; from the Ramón Areces Foundation: XVII Edition on Rare Diseases; and from Generalitat de Catalunya through the CERCA program. J.A., P.L., and A.M. acknowledge funding from the Foundation La Marató de TV3: ref. 20141730.
\end{abstract}

\section{Author details}

${ }^{1}$ Department of Physiological Sciences, University of Barcelona School of Medicine - Health Science Campus of Bellvitge, L'Hospitalet de Llobregat, 08907 Barcelona, Spain. ${ }^{2}$ Institute of Neurosciences, University of Barcelona, Castelldefels, 08035 Barcelona, Spain. ${ }^{3}$ Institut d'Investigació Biomèdica de Bellvitge - IDIBELL, L'Hospitalet de Llobregat, Castelldefels, 08908 Barcelona, Spain. ${ }^{4}$ ICFO-Institut de Ciències Fotoniques, The Barcelona Institute of Science and Technology, Castelldefels, 08860 Barcelona, Spain. ${ }^{5}$ Centres Cientifics i Tecnològics (CCiTUB), University of Barcelona, Castelldefels, 08036 Barcelona, Spain. ${ }^{6}$ Physiology Unit, Dept of Systems Biology, School of Medicine, University of Alcalá, Alcalá de Henares, 28805 Madrid, Spain. Visual Neurophysiology Group-IRYCIS, Madrid, Spain

\section{Author contributions}

Conceived and designed the experiments: A.P.B., S.L.B., PdI.V., and A.M. Performed the experiments: A.P.B., S.L.B., PdI.V., J.A., P.L., M.J.F., J.M.E., and A.M. Analyzed the data: S.L.B., A.P.B., Pdl.V., and A.M. Wrote the paper: A.M.

\section{Conflict of interest}

The authors declare that they have no conflict of interest.

\section{Publisher's note}

Springer Nature remains neutral with regard to jurisdictional claims in published maps and institutional affiliations.

Supplementary Information accompanies this paper at (https://doi.org/ 10.1038/s41419-020-2255-0)

Received: 5 November 2019 Revised: 9 January 2020 Accepted: 10 January 2020

Published online: 24 January 2020

\footnotetext{
References

1. Burns, M. E. \& Arshavsky, V. Y. Beyond counting photons: trials and trends in vertebrate visual transduction. Neuron 48, 387-401 (2005).
}

2. Arshavsky, V. Y. \& Burns, M. E. Photoreceptor signaling: supporting vision across a wide range of light intensities. J. Biol. Chem. 287, 1620-1626 (2012).

3. Perrault, I. et al. Retinal-specific guanylate cyclase gene mutations in Leber's congenital amaurosis. Nat. Genet. 14, 461-464 (1996).

4. Payne, A. et al. A mutation in guanylate cyclase activator $1 A$ (GUCA1A) in an autosomal dominant cone dystrophy pedigree mapping to a new locus on chromosome 6p21.1. Hum. Mol. Genet. 7, 273-277 (1998).

5. Kelsell, R. E. et al. Mutations in the retinal Guanylate Cyclase (RetGC-1) gene in dominant cone-rod dystrophy. Hum. Mol. Genet. 7, 1179-1184 (1998).

6. Marino, V. et al. A novel p.(Glu111Val) missense mutation in GUCA1A associated with cone-rod dystrophy leads to impaired calcium sensing and perturbed second messenger homeostasis in photoreceptors. Hum. Mol. Genet. 27, 4204-4217 (2018)

7. Kitiratschky, V. B. D. et al. Mutations in the GUCA1A gene involved in hereditary cone dystrophies impair calcium-mediated regulation of guanylate cyclase. Hum. Mutat. 30, E782-E796 (2009).

8. Michaelides, M. et al. Mutation in the gene GUCA1A, encoding Guanylate Cyclase-Activating Protein 1, causes cone, cone-rod, and macular dystrophy. Ophthalmology 112, 1442-1447 (2005).

9. Wilkie, S. E. et al. Identification and functional consequences of a new mutation (E155G) in the gene for GCAP1 that causes autosomal dominant cone dystrophy. Am. J. Hum. Genet. 69, 471-480 (2001).

10. Vocke, F. et al. Dysfunction of CGMP signalling in photoreceptors by a macular dystrophy-related mutation in the calcium sensor GCAP1. Hum. Mol. Genet. 26, ddw374 (2016).

11. Peshenko, I. V. et al. A G86R mutation in the calcium-sensor protein GCAP1 alters regulation of retinal guanylyl cyclase and causes dominant cone-rod degeneration. J. Biol. Chem. 294, 3476-3488 (2019).

12. Jiang, L. et al. A novel GCAP1(N104K) mutation in EF-hand 3 (EF3) linked to autosomal dominant cone dystrophy. Vis. Res. 48, 2425-2432 (2008).

13. Chang, B., Heckenlively, J. R., Hawes, N. L. \& Roderick, T. H. New mouse primary retinal degeneration (rd-3). Genomics 16, 45-49 (1993).

14. Friedman, J. S. et al. Premature truncation of a novel protein, RD3, exhibiting subnuclear localization is associated with retinal degeneration. Am. J. Hum. Genet. 79, 1059-1070 (2006).

15. Azadi, S., Molday, L. L. \& Molday, R. S. RD3, the protein associated with Leber congenital amaurosis type 12 , is required for guanylate cyclase trafficking in photoreceptor cells. Proc. Natl Acad. Sci. USA 107, 21158-21163 (2010).

16. Dizhoor, A. M., Olshevskaya, E. V. \& Peshenko, I. V. Mg2+/Ca2+ cation binding cycle of guanylyl cyclase activating proteins (GCAPs): role in regulation of photoreceptor guanylyl cyclase. Mol. Cell. Biochem. 334, 117-124 (2010).

17. Peshenko, I. V. et al. Enzymatic properties and regulation of the native isozymes of retinal membrane guanylyl cyclase (RetGC) from mouse photoreceptors. Biochemistry 50, 5590-5600 (2011).

18. Makino, C. L. et al. Enzymatic relay mechanism stimulates cyclic GMP synthesis in rod photoresponse: biochemical and physiological study in Guanylyl Cyclase Activating Protein 1 knockout mice. PLOS ONE 7, e47637 (2012).

19. Méndez, A. et al. Role of guanylate cyclase-activating proteins (GCAPS) in setting the flash sensitivity of rod photoreceptors. Proc. Natl. Acad. Sci. USA 98, 9948-9953 (2001).

20. Burns, M. E., Méndez, A., Chen, J. \& Baylor, D. A. Dynamics of cyclic GMP synthesis in retinal rods. Neuron 36, 81-91 (2002).

21. Baehr, W. et al. The function of Guanylate Cyclase 1 and Guanylate Cyclase 2 in rod and cone photoreceptors. J. Biol. Chem. 282, 8837-8847 (2007).

22. López-Begines, S. Plana-Bonamaisó, A. \& Méndez, A. Molecular determinants of Guanylate Cyclase Activating Protein subcellular distribution in photoreceptor cells of the retina. Sci. Rep. 8, 2903 (2018).

23. Jacobson, S. G. et al. Determining consequences of retinal membrane guanylyl cyclase (RetGC1) deficiency in human Leber congenital amaurosis en route to therapy: residual cone-photoreceptor vision correlates with biochemical properties of the mutants. Hum. Mol. Genet. 22, 168-183 (2013).

24. Linberg, K. A., Fariss, R. N., Heckenlively, J. R., Farber, D. B. \& Fisher, S. K. Morphological characterization of the retinal degeneration in three strains of mice carrying the rd-3 mutation. Vis. Neurosci. 22, 721-734 (2005).

25. Peshenko, I. V. et al. Retinal Degeneration 3 (RD3) protein inhibits catalytic activity of retinal membrane Guanylyl Cyclase (RetGC) and its stimulation by activating proteins. Biochemistry 50, 9511-9519 (2011).

26. López del Hoyo, N., López-Begines, S., Rosa, J. L., Chen, J. \& Méndez, A. Functional EF-hands in neuronal calcium sensor GCAP2 determine its phosphorylation state and subcellular distribution in vivo, and are essential for photoreceptor cell integrity. PLoS Genet. 10, e1004480 (2014). 
27. Danciger, M. et al. Genetic modifiers of retinal degeneration in the rd3 Mouse. Investig. Opthalmology Vis. Sci. 49, 2863-2869 (2008).

28. Molday, L. L. et al. RD3 gene delivery restores guanylate cyclase localization and rescues photoreceptors in the Rd3 mouse model of Leber congenital amaurosis 12. Hum. Mol. Genet. 22, 3894-3905 (2013).

29. Dizhoor, A. M., Olshevskaya, E. V. \& Peshenko, I. V. Retinal guanylyl cyclase activation by calcium sensor proteins mediates photoreceptor degeneration in an rd3 mouse model of congenital human blindness. J. Biol. Chem. 294, 13729-13739 (2019)

30. Peshenko, I. V., Olshevskaya, E. V. \& Dizhoor, A. M. Ca ${ }^{2+}$-dependent conformational changes in guanylyl cyclase-activating protein 2 (GCAP-2) revealed by site-specific phosphorylation and partial proteolysis. J. Biol. Chem. 279, 50342-50349 (2004).

31. Oyadomari, S. \& Mori, M. Roles of CHOP/GADD153 in endoplasmic reticulum stress. Cell Death Differ. 11, 381-389 (2004).

32. $\mathrm{Ma}, \mathrm{H}$. et al. cGMP/Protein Kinase $\mathrm{G}$ signaling suppresses inositol 1,4,5-trisphosphate receptor phosphorylation and promotes endoplasmic reticulum stress in photoreceptors of cyclic nucleotide-gated channel-deficient mice. J. Biol. Chem. 290, 20880-20892 (2015).

33. Thapa, A. et al. Endoplasmic reticulum stress-associated cone photoreceptor degeneration in cyclic nucleotide-gated channel deficiency. J. Biol. Chem. 287 18018-18029 (2012).

34. Butler, M. R. et al. Endoplasmic reticulum (ER) Ca ${ }^{2+}$-channel activity contributes to ER stress and cone death in cyclic nucleotide-gated channel deficiency. J. Biol. Chem. 292, 11189-11205 (2017).
35. Cheng, C. L. \& Molday, R. S. Changes in gene expression associated with retina degeneration in the rd3 mouse. Mol. Vis. 19, 955-969 (2013).

36. Plotegher, N. et al. The chaperone-like protein 14-3-3n interacts with human a-synuclein aggregation intermediates rerouting the amyloidogenic pathway and reducing a-synuclein cellular toxicity. Hum. Mol. Genet. 23, 5615-5629 (2014).

37. Yacoubian, T. A. et al. Differential neuroprotective effects of 14-3-3 proteins in models of Parkinson's disease. Cell Death Dis. 1, e2-e2 (2010).

38. Kuijpers, M. et al. Dynein regulator NDEL1 controls polarized cargo transport at the axon initial segment. Neuron 89, 461-471 (2016).

39. Inaba, $\mathrm{H}$. et al. Ndel1 suppresses ciliogenesis in proliferating cells by regulating the trichoplein-Aurora A pathway. J. Cell Biol. 212, 409-423 (2016).

40. Méndez, A. et al. Role of guanylate cyclase-activating proteins (GCAPs) in setting the flash sensitivity of rod photoreceptors. Proc. Natl. Acad. Sci. USA 98 9948-9953 (2001)

41. Zybailov, B. et al. Statistical analysis of membrane proteome expression changes in Saccharomyces cerevisiae research articles. J. Proteome Res. 5, 2339-2347 (2006)

42. Matsuda, T. \& Cepko, C. L. Electroporation and RNA interference in the rodent retina in vivo and in vitro. Proc. Natl Acad. Sci. USA https://doi.org/10.1073/ pnas.2235688100 (2004).

43. Zack, D. J. et al. Unusual topography of bovine rhodopsin promoter-lacZ fusion gene expression in transgenic mouse retinas. Neuron 6, 187-199 (1991). 